\title{
"AMERICA FIRST BUT NOT ALONE": UMA (NEM TÃO) NOVA POLÍTICA COMERCIAL DOS ESTADOS UNIDOS COM DONALD TRUMP
}

\author{
Filipe Mendonça ${ }^{1}$ \\ Lais Forti Thomaz ${ }^{2}$ \\ Thiago Lima $^{3}$ \\ Tullo Vigevani ${ }^{4}$
}

\begin{abstract}
Este artigo examina a política comercial dos Estados Unidos na primeira metade do governo de Donald J. Trump (2017-2018). Afirmamos que, do ponto de vista estrutural, tal política segue seu curso histórico com semelhanças importantes quando comparada à de Ronald Reagan e à consolidação do instrumento conceitual de Fair Trade. Nesse sentido, a administração Trump é uma revisitação daquele período, com um estilo de negociação do presidente, em grande medida sustentado pelo que chamamos de "America first but not alone". Isso significa que, embora 0 neomercantilismo de Trump tenha características inéditas, essa nova fase da política comercial norte-americana parece insuficiente em sua missão de promover inflexões estruturais.
\end{abstract}

Palavras-chave: Estados Unidos; política comercial; Donald Trump; neomercantilismo.

\section{"AMERICA FIRST BUT NOT ALONE": A (NOT SO) NEW US TRADE POLICY WITH DONALD TRUMP}

This article examines United States trade policy in the first half of Donald Trump's government (2017-2018). We concluded that, from the structural point of view, the United States trade policy follows its historical course. While the Trump Administration is a kind of a new radical step, there is no structural change from the aggressive unilateralism trade policy, largely supported by what we call "America first but not alone". This means that although Donald Trump's neo-mercantilism has unprecedented features, the current United States trade policy appears to be insufficient in its mission to promote structural inflections. To do so, we demonstrate how the trade war with China and the renegotiation of North American Free Trade Agreement (NAFTA) took place.

Keywords: United States; comercial policy; Donald Trump; neomercantilism.

\section{"AMERICA FIRST BUT NOT ALONE": UNA (NO TAN) NUEVA POLÍTICA COMERCIAL DE ESTADOS UNIDOS CON DONALD TRUMP}

Este artículo examina la política comercial de los Estados Unidos en la primera mitad del gobierno de Donald J. Trump (2017-2018). Afirmamos que, desde un punto de vista estructural, la política

1. Professor da Universidade Federal de Uberlândia (UFU); e pesquisador do Instituto Nacional de Ciência e Tecnologia para Estudos sobre os Estados Unidos (INCT-INEU).E-mail: <mendonca@ufu.br>.

2. Professora da Universidade Federal de Goiás (UFG); e pesquisadora do INCT-INEU. E-mail: <laisthomaz@ufg.br>.

3. Professor da Universidade Federal da Paraíba (UFPB); e pesquisador do INCT-INEU.E-mail: <tlima@ccsa.ufpb.br>.

4. Professor da Universidade Estadual Paulista Júlio de Mesquita Filho (Unesp); e pesquisador do INCT-INEU.

E-mail: <vigevanit@uol.com.br>. 
comercial de Estados Unidos sigue su curso histórico con importantes similitudes en comparación con la de Reagan y la consolidación del instrumento conceptual de Comercio Justo. En este sentido, la administración Trump es una revisión de ese período, con un estilo de negociación del presidente, respaldado en gran medida por lo que llamamos "America first but not alone". Esto significa que si bien el neo-mercantilismo de Trump tiene características sin precedentes, la nueva fase de la política comercial de Estados Unidos parece insuficiente en su misión de promover inflexiones estructurales.

Palabras clave: Estados Unidos; política comercial; Donald Trump; neomercantilismo.

JEL: F13; D72.

\section{INTRODUÇÃO}

A chegada de Donald J. Trump à presidência dos Estados Unidos foi surpreendente. Poucos poderiam imaginar que um candidato com um discurso abertamente mercantilista ganharia os votos necessários para obter maioria do colégio eleitoral. Evidentemente, os motivos que podem determinar o voto são variados. Quando olhamos para as questóes econômicas, entretanto, nota-se que os prejudicados pela "hiperglobalização" fizeram sentir seu protesto em voz alta. As pressóes protecionistas ganharam, portanto, relevância e apoio por questionarem a distribuição assimétrica dos ganhos. Segundo Parilla e Muro (2016), as cidades mais afetadas pela concorrência internacional votaram em Trump em 90\% dos casos. Além disso, a eleição presidencial de novembro de 2016 mostrou também como interesses corporativos de grandes grupos e interesses estratégicos não são suficientes para conquistar apoio de todos os setores da população. A perspectiva liberal e os grupos e setores afetados travam um embate que está longe de alcançar uma definição (Rodrik, 2018).

Diante desse quadro, parece ser insuficiente o termo nacionalista para distinguir Trump de outros presidentes, mesmo com seu mote de campanha, America First (Os Estados Unidos primeiro). Cada um a seu modo, do pós-Segunda Guerra Mundial em diante, todos os presidentes defenderam a liderança da economia dos Estados Unidos, num contexto de integração à economia mundial, assim como a internacionalização de normas liberalizantes, sempre a partir uma perspectiva nacionalista e hegemônica (Mendonça, Lima e Vigevani, 2018). Colocar e manter a economia dos Estados Unidos no centro do tabuleiro fez parte do projeto nacional e hegemônico do país durante boa parte do século XX, assegurando com isso as rédeas do capitalismo globalizado, conceito que se generaliza a partir da década de 1980 (Rosecrance, 1986).

É inegável, contudo, que Trump parece operar em outra chave. Ele traz um discurso mercantilista/realista próprio dos manuais de economia política internacional do mainstream das relaçôes internacionais: jogos de soma-zero, interdependência como vulnerabilidade, produção industrial nacional como atributo de poder. Livre-comércio e acordos de liberalização interessam, desde que 
tragam vantagens, no caso atual, melhorem a balança comercial de manufaturas, e garantam um acúmulo estratégico, com repercussóes diretas no tocante à busca da manutenção da supremacia nas áreas tecnológica e de segurança. As relações econômicas com China, Japão e União Europeia (UE), e também as relações militares com a Rússia, podem ser assim mais bem entendidas.

Com esse cenário, a questão que surge com frequência, do ponto de vista da política comercial dos Estados Unidos, é se estaríamos diante de um momento de inflexão histórica. Esse questionamento tem fôlego: pelo menos desde o pós-Segunda Guerra Mundial, um presidente engajado na liberalização comercial, embora sempre de forma seletiva, por meio de um sistema multilateral foi um dos mais importantes vetores da política comercial dos Estados Unidos, mesmo diante dos impulsos protecionistas que passaram a surgir e se acumularam na sociedade estadunidense desde os anos 1960. É preciso, porém, ter cautela no ineditismo argumentativo. Ainda que a história não se repita, a comparação das medidas adotadas pelo governo Donald Trump com o período Ronald Reagan ajuda muito a pensar os acontecimentos em perspectiva delongo prazo, de forma estrutural, situando os acontecimentos das décadas iniciais do século XXI num contexto maior. A lembrança desse período, especialmente entre 1981 e 1992, é claramente importante para entender alguns dos parâmetros do debate que ocorre e deverá se aprofundar ao longo de toda a administração Trump, ainda que, atualmente, o posicionamento dos atores não seja o mesmo.

Nesse sentido, argumentamos que o trumpismo não deve ser considerado um rompimento com a complexa arquitetura de multilateralismo liberal construído ao longo de mais de setenta anos, 1944 (ou antes) até 2016. Como dissemos, com Trump há características inéditas, mas a nova fase da política comercial dos Estados Unidos parece insuficiente na sua missão de promover inflexôes estruturais. Mesmo diante de um presidente que insiste, de forma discursiva talvez mais que outros, em colocar os Estados Unidos em primeiro lugar, os resultados e eventuais mudanças dependem sempre das relações de poder tanto no âmbito interno como externo (but not alone). São essas relaçôes e suas possíveis consequências que acabarão por determinar o destino do comércio. Esse tabuleiro, em constante movimento, está longe de uma definiçẫo. Não obstante, o núcleo do trumpismo, no que tange à política comercial, deixa claro seus objetivos, busca reformatar as relaçóes e a distribuição de ganhos, e pretende recuperar as perdas econômicas, sobretudo a liderança estratégica, que afirmam ter perdido em algum momento no passado.

Esse argumento pode parecer contraintuitivo. Afinal, não se pode ignorar o discurso duro do novo governo contra o deficit comercial dos Estados Unidos, as "regras multilaterais de comércio", que não seriam condizentes com o poder norte-americano, e o comércio injusto (unfair trade). É nesse ponto que recai a maior parte das análises conjunturais. Como já discutimos (Mendonça, Lima e 
Vigevani, 2017, p. 71), o estudo da política comercial dos Estados Unidos precisa levar em consideração as trajetórias históricas, os desenvolvimentos do cenário político internacional, a situação econômica, a política doméstica e as ideias relativas ao comércio. Em outras palavras, é preciso considerar as influências tanto no âmbito doméstico como no internacional, sempre em perspectiva histórica. Esse recorte analítico nos dá recursos para analisar as açôes nos dois primeiros anos do novo governo, com destaque para o design institucional de formulação de política comercial e o fortalecimento dos mecanismos de enforcement.

Nessesentido, argumentamosque a administração Trump busca, em seus próprios termos, colocar o sistema multilateral de comércio "de volta nos trilhos". A nova equipe busca uma série de revisionismos nos acordos já firmados pelos Estados Unidos, além de dar vazão ao discurso protecionista com a criação de novas barreiras. A posição ocupada pelo país na ordem econômica global, entretanto, impóe limites às açôes do trumpismo. Essa tensão entre as pressões domésticas e o papel global dos Estados Unidos como principal potência econômica tem provocado o aprofundamento das políticas de enforcement pela via unilateral e "guerras comerciais". As medidas tomadas por Trump na primeira metade de seu governo parecem corroborar essa hipótese, uma vez manifesta a preferência pela via unilateral em detrimento de mecanismos multilaterais, como o Órgão de Solução de Controvérsias (OSC) da Organização Mundial do Comércio (OMC). Dessa forma, o clima de "caça às bruxas" fortalece o uso da política comercial como instrumento de projeção de normas e princípios estadunidenses (Murphy, 2014), e como canal de escoamento de demandas internas de grupos econômicos afetados pela competição externa.

Além desta introdução, o texto está organizado da seguinte forma: a segunda seção faz alguns breves apontamentos históricos. A intenção é mostrar que o trumpismo comercial apresenta fortes antecedentes históricos, com destaque para o reaganismo comercial e sua intensificaçâo do discurso do Fair Trade e do unilateralismo agressivo, e para a criação de dispositivos domésticos de retaliação. Essas ideias perdem força no período neoliberal, durante os governos de Bill Clinton e de George W. Bush. A crise financeira de 2008 e a ascensão da China criaram, entretanto, um ambiente fértil para o retorno do discurso do Fair Trade ainda no governo Barack Obama, ganhando força em 2016 durante as eleições e avançando em sua institucionalização com a chegada de Donald Trump ao poder.

A terceira seção buscará demonstrar a distribuição de poder entre as burocracias do Executivo na formulação da política comercial dos Estados Unidos. De certo modo, o perfil de secretários de departamento, conselheiros e assessores de alto nível reflete a disputa de ideias no interior da coalizão política, econômica e social que apoia o presidente. No caso da administraçáo iniciada em janeiro de 2017, no que tange às políticas de comércio internacional, chamam 
atenção três pessoas: i) o assessor Peter Navarro; ${ }^{5}$ ii) o secretário de comércio Wilbur Ross; ${ }^{6}$ e iii) o chefe do escritório do Representante Comercial dos Estados Unidos (United States Trade Representative - USTR), Robert Lighthizer.

A quarta seção deste artigo faz um resgate das principais decisóes de comércio do novo governo, como a saída do Acordo de Parceria Transpacífica (Trans-Pacific Partnership - TPP), a renegociação do Acordo de Livre-Comércio da América do Norte (North American Free Trade Agreement - NAFTA), as investigaçôes para combater "práticas injustas" de comércio no âmbito do USTR etc. Já a política de retaliação via tarifas será considerada nas seis ondas de 2018, retomando a periodizaçấo sugerida por Amiti, Redding e Weinstein (2019): a primeira iniciada em janeiro, a segunda em março, a terceira em junho, a quarta em julho, a quinta em agosto e a última em setembro, todas em 2018. Ao todo, a política tarifária de Trump atingiu US\$ 283 bilhôes em importações dos Estados Unidos, com taxas que variam entre 10\% e 50\% (Amiti, Redding e Weinstein, 2019).

A quinta seção deste estudo mostra a reação doméstica e internacional à política comercial de Trump. O trumpismo, como processo negociador, consolida mudanças importantes, mas sem possibilidade de identificar nisso o fim do sistema multilateral construído a partir de 1944. Estaria-se diante de uma forte radicalização do próprio sistema? Além desse questionamento, este texto buscou mostrar a baixa elasticidade do deficit estadunidense, mesmo com as retaliaçóes cruzadas, bem como as feiçóes apartidárias que as políticas de Fair Trade têm conquistado no sistema político do país nos últimos anos.

$\mathrm{Na}$ última seção, alguns breves apontamentos finais consolidarão as conclusóes já indicadas ao longo deste estudo.

\section{UM BREVE ANTECEDENTE}

A comparação da política comercial com a década de 1980 é inevitável. Entre as inúmeras periodizaçóes possíveis da política comercial dos Estados Unidos, uma fase se destaca: aquela que vigorou entre 1979 e 1988. Esse período foi marcado por uma nova concepção de política comercial, com a utilização recorrente

5. Peter Navarro é formado pela Universidade de Tufts (1972) e é doutor em Economia por Harvard (1986). Foi professor de Economia e Políticas Públicas na Escola de Negócios Paul Merage, na Universidade da Califórnia-Irvine, por vinte anos.

6. Wilbur Louis Ross Jr. é o atual secretário de comércio da administração Trump e uma de suas principais vozes. Trabalhou por 24 anos (1976 a 2000) para o banco de investimentos Rothschild Inc. Nos anos 2000, abriu sua própria empresa de private equity, isto é, de gestão de investimentos, que fornece suporte financeiro e investe no capital de empresas iniciantes ou já consolidadas, a WL Ross \& Co. LLC. Pouco depois, fundou o International Steel Group (ISG). Além disso, foi presidente ou diretor principal de mais de cem empresas que operam em mais de vinte países. Segundo Lerner (2018), a firma do magnata, WL Ross \& Co. LLC, realizou aquisições de empresas do ramo siderúrgico em processo de falência ou próximas disso, como a LTV Corporation, a Weirton e a Bethlehem Steel, consolidando-as no ISG e vendendo-as, em 2004, para a empresa indiana de aço de Lakshmi Mittal, ganhando cerca de US\$ 2 bilhões nessa negociação. 
de medidas unilaterais por parte dos Estados Unidos contra os seus principais competidores econômicos. Exemplo marcante desse período é o uso do conceito de Fair Trade e a utilização da seçáo 301 do Trade Act de 1974, com a qual o USTR exigia a abertura de setores econômicos de parceiros comerciais sob pena de impor restriçôes de acesso ao mercado dos Estados Unidos (Mendonça, 2011).

O período do Fair Trade, que se inicia em meados da década de 1980, é, em boa parte, resultado das mudanças econômicas e produtivas estruturais e consequentes realinhamentos domésticos. Entre as diversas mudanças ocorridas, talvez as mais importantes sejam a nova interpretaçáo da ideia de reciprocidade e o combate ao que se entendia por comércio desleal, ensaiados na década de 1970 e colocados em prática com maior intensidade nesse período. No plano estratégico, uma visão diferenciada sobre a Guerra Fria diminuiu a aceitação dos custos assimétricos das relaçôes comerciais, sobretudo no segundo governo Reagan (Destler, 2005, p. 61). No campo econômico, a deterioração agravou-se ainda mais, principalmente no primeiro governo Reagan, quando impostos foram reduzidos e os gastos aumentados, muito por conta do programa Guerra nas Estrelas, que injetou recursos em setores de tecnologia de ponta. Essa combinação de políticas macroeconômicas contribuiu para os deficit orçamentário e comercial. Por mais que problemas de competitividade tivessem pouca relação com políticas adotadas em outros países e pudessem ser mais atribuídos ao valor do dólar - e mesmo à precariedade em inovação de cadeias produtivas do setor privado -, culpar outros países de deslealdade e exigir uma atitude mais agressiva e nacionalista da administração eram posturas que geravam apelo eleitoral. As dificuldades econômicas estimularam a atuação de grupos de interesses em situação mais difícil a pressionar congressistas por mudanças políticas. Demandava-se, ex post, reciprocidade dos parceiros comerciais.

O período de Fair Trade do tipo reaganiano ${ }^{7}$ foi interrompido por um longo consenso neoliberal que compreendeu os governos George Bush, Bill Clinton e George W. Bush - abordado em detalhes em trabalhos anteriores (Vigevani, Mendonça e Lima, 2018). A ascensão chinesa após sua adesão à OMC, em 2001, e, mais tarde, a crise de 2008 parecem, entretanto, ter criado um ambiente propício para uma nova fase de Fair Trade, que já dava sinais modestos na administraçâo Barack Obama, embora ainda prevalecesse o conceito de ampla globalização. Os sinais se tornaram evidentes nos programas das duas candidaturas em 2016, atingindo um pico no início da gestão Trump.

O contexto pós-crise de 2008 fez com que o primeiro mandato de Obama fosse marcado por uma postura menos ambiciosa, com dificuldades de geração de consenso no Congresso e baixa capacidade de construção de uma agenda comercial liberalizante. Como resultado dessa combinação, Obama concentrou

7. Tal política foi largamente descrita em trabalhos anteriores por Mendonça (2011) e Mendonça, Lima e Vigevani (2017; 2018). 
esforços na geração de empregos e em temas relacionados ao comércio, quando tiveram início o debate e as negociaçóes visando aos mega-acordos, mas não no quadro da OMC. A difícil conjuntura política e econômica em que o país se encontrava no início de seu primeiro mandato fortaleceu insatisfaçóes quanto aos rumos da política comercial, em grande medida por conta da crise do subprime e do desemprego dela decorrente. Havia, portanto, uma "percepção de rejeiçấo do público estadunidense, em especial do eleitorado democrata, à realização de acordos de liberalização comercial” (Mendonça e Lima, 2017, p. 2), o que contribuiu para o impasse e a paralisia na Rodada Doha. Internamente refletiu-se na candidatura Bernie Sanders e na inflexão mais protecionista de Hillary Clinton.

Com o esgotamento da via multilateral, Obama concentrou-se em mecanismos domésticos. Somado à tradicional defesa da superioridade técnica do livre-comércio e à histórica ênfase no deficit comercial por parte de diversos atores políticos daquele país, esse conjunto de fatos - crise da Rodada Doha, crise financeira, pressão para geração de emprego, entre outros - fez com que a política comercial do governo Obama enfatizasse aspectos como as políticas de enforcement. Entre 2009 e 2015, os Estados Unidos entraram vinte vezes como demandantes junto ao OSC da OMC, com alta taxa de sucesso. Nessas iniciativas, a China constituiu o principal alvo (onze casos). Embora esse número náo diferencie substancialmente o governo Obama de seu antecessor, George W. Bush, um elemento inovador foi a criação do International Trade Enforcement Center (ITEC) em 2012, uma burocracia especializada no reforço e na aplicação dos direitos comerciais sob a ótica estadunidense, e a elaboração de estratégias de convencimento - pela ameaça de retaliação ou pelo diálogo - de países considerados desleais em termos comerciais. Desde a sua criação, o ITEC reuniu uma equipe voltada a fomentar o respeito às obrigaçóes no âmbito da OMC, interpretadas de acordo com os interesses nacionais, além de promover a produção e as exportaçóes dos Estados Unidos.

Entre o primeiro e o segundo mandato de Obama, a ambição em termos comerciais parece ter aumentado, rompendo com a postura de baixo perfil e deixando um legado de peso para o presidente seguinte. Aqui, destacam-se a intensificaçẫo da postura crítica de parte da opinião pública dos Estados Unidos em relação às negociações comerciais multilaterais e a aprovação, em 2015, da Autoridade para Promoção Comercial (Trade Promotion Authority - TPA, também conhecida como fast track). Uma das principais dificuldades em avançar na Rodada Doha, que seria símbolo de fôlego e continuidade do multilateralismo, segundo o governo estadunidense, foi o papel "intransigente" desempenhado por países em desenvolvimento de médio porte e suas coalizóes (Schwab, 2011).

Nesse contexto de crise do arranjo multilateral, Obama consolidou a estratégia de recuo do nível multilateral e investiu esforços e recursos em outras 
direçóes, com destaque para os mega-acordos - o que chamamos de "saídas oceânicas" (Mendonça e Lima, 2017), ou seja, a solução pelo oceano Pacífico, via TPP; e pelo oceano Atlântico, via Acordo de Parceria Transatlântica de Comércio e Investimento (Transatlantic Trade and Investment Partnership - TTIP).

Diante desse cenário, o clima político nas eleiçóes de 2016 era de "caça às bruxas" nas duas campanhas, com destaque especial para o papel da China, entendida como a principal violadora do regime multilateral de comércio. $\mathrm{Na}$ mesma lógica, o já consolidado NAFTA passou a ser objeto de propostas de revisão dos dois candidatos, bem como o TPP. A escolha da China e do NAFTA como principais alvos não foi aleatória, particularmente de parte da campanha republicana. Somados, os três países (China, México e Canadá) representavam 47,21\% das importações dos Estados Unidos em 2016 e 56,31\% do deficit na balança comercial (tabela A.1 do apêndice). Depois do recuo em 2008 e um ainda maior em 2009, o produto interno bruto (PIB) estadunidense foi sempre positivo em todo o período Obama.

Embora com diferenças metodológicas importantes, Hillary Clinton e Donald Trump afirmavam que, caso eleitos, buscariam a centralidade dos Estados Unidos nos processos políticos e econômicos internacionais. Para isso, pretendiam usar a política comercial como instrumento de projeção de normas e princípios estadunidenses nos regimes multilaterais, e também como canal de escoamento de demandas internas de grupos econômicos afetados pela competição externa.

As duas candidaturas se colocavam, portanto, cada uma a seu modo, como críticas da política comercial do antecessor Barack Obama. Como a política comercial envolve necessariamente outros países e parceiros, a equação evidenciou-se mais complexa, uma vez concluído o processo eleitoral. A análise dos discursos dos presidenciáveis, no entanto, deu o tom da dimensão das possibilidades internas de sustentação da política comercial como um todo, e apontava para possibilidades de inflexôes das trajetórias adotadas até aqui.

\section{TRUMPISMO, AS IDEIAS E A CONSTITUIÇÃO DO PODER NA ÁREA DO COMÉRCIO INTERNACIONAL}

Para entender como o ímpeto neomercantilista se transforma em política pública, um fator de destaque a considerar é a distribuição de poder entre as burocracias do Executivo (Destler, 2005). De certo modo, o perfil de secretários de departamento, conselheiros e assessores de alto nível reflete a disputa de ideias no interior da coalizão política, econômica e social que apoia o presidente. No caso da administraçáo iniciada em janeiro de 2017 , no que tange às políticas de comércio internacional, chamam atenção três pessoas: o assessor Peter Navarro, o secretário de comércio Wilbur Ross e o chefe do escritório do USTR Robert Lighthizer. 
Inicialmente, Navarro foi apontado para liderar o Conselho Nacional do Comércio (National Trade Council - NTC) da Casa Branca. Um remanejamento, contudo, acabou eliminando o conselho e criando o Escritório de Política Comercial e Industrial (Office of Trade and Manufacturing Policy - OTMP), comandado por Navarro, mas que funciona subordinado ao Conselho Econômico Nacional (National Economic Council - NEC), então sob liderança de Gary Cohn, egresso do Goldman Sachs, onde foi presidente e diretor de operaçôes, considerado pela mídia um defensor da liberalização comercial que desempenhava um papel de contrapeso a Navarro na administração. Após a imposição de tarifas a uma série de países, no entanto, Cohn acabou se demitindo.

Navarro sempre se mostrou crítico às políticas econômicas da China e aos acordos e blocos comerciais de que os Estados Unidos fazem parte atualmente (Helmore, 2018). Trump descrevia Navarro como um economista visionário que reduziria o deficit comercial dos Estados Unidos por meio do desenvolvimento de políticas comerciais que permitiriam o crescimento econômico, além da diminuiçâao do desemprego. Já no final dos anos 1990, incomodado pelo acelerado progresso chinês, Navarro denunciava os riscos da entrada da China na OMC, o que se concretizaria em 2001. Desde então, dedicou-se intensamente ao estudo da economia chinesa e de seus efeitos nos Estados Unidos e no mundo, escrevendo inúmeros artigos e livros, entre os quais Death by China, mais tarde adaptado para um documentário homônimo largamente difundido em serviços de streaming. ${ }^{8}$ De acordo com Ball (2018), Navarro afirmou, em junho de 2018: "perdemos a guerra comercial décadas atrás, quando entramos no NAFTA e deixamos a China entrar na OMC". Navarro também se colocou como um ferrenho crítico do NAFTA, defendendo o fim do acordo e a retirada dos Estados Unidos do TPP (Solomon, 2018).

Wilbur Louis Ross Jr. é um investidor com interesses nas indústrias do aço e do carváo, e fundador do ISG. Desde dezembro de 2008, Ross ocupou a posição de diretor de gestão de investimentos na WLR China Energy Associates Ltd., localizada nas Ilhas Cayman, além de exercer funçóes em outras empresas e corporaçóes com capital proveniente de diferentes países. ${ }^{9}$ Após as decisões a respeito das sobretaxas ao aço importado, anunciadas pelo Departamento de Comércio, investigaçóes já existentes em torno dos negócios de empresas do setor com as quais Wilbur Ross mantinha vínculos e a caracterização de possíveis

8. Depois de observar os efeitos do ingresso da China na OMC, Peter Navarro acusa esse país de responsável pelo desequilíbrio comercial mundial e de práticas econômicas desleais, como manipulação da moeda, roubo de propriedade intelectual (estadunidense) e poluição do meio ambiente. Afirma, também, que os chineses estão travando uma guerra econômica contra os Estados Unidos, valendo-se de subsídios à exportação, restrição às importações e manipulações cambiais que incentivam o crescimento econômico interno chinês. Ainda segundo Navarro, ajudados pela demografia e pelo não respeito do governo pelas regulamentações internacionais de trabalho, a China exporta seus produtos com preços menores, elevando seu status à potência econômica mundial (Navarro e Autry, 2011).

9. Informação disponível em: <https://bit.ly/2jvYKWY>. 
conflitos de interesse ganharam relevância. Em 2018, o Campaign Legal Center (CLC), sediado em Washington, informou que, entre 2017 e 2018, os relatórios periódicos de transaçóes relativas a vendas de ativos apresentados por Ross não refletiam o total dos desinvestimentos com os quais estava comprometido em razão de ter assumido o cargo de secretário de comércio no governo. Especificamente, 35 ativos - incluindo a WLR China Energy Associates Ltd. -, os quais deveriam ter sido alienados no prazo de 180 dias a partir de sua posse, não figuraram nos relatórios. ${ }^{10}$ Segundo Sanchez (2018a), uma das aquisiçôes de Ross foi realizada apenas uma semana antes de o ex-presidente George W. Bush impor tarifas sobre o aço importado, elevando seu valor.

Da mesma forma que Peter Navarro, Wilbur Ross sempre se mostrou crítico de acordos comerciais dos quais os Estados Unidos fazem parte e dos quais foram promotores determinantes. O NAFTA, o TPP e a OMC foram vistos como "mal negociados". Em uma conferência de imprensa em abril de 2017, o secretário de comércio afirmou que

é anômalo que os Estados Unidos, com seu enorme deficit comercial, tenham relativamente menos acordos de livre-comércio do que países muito menores, como o México. E acho que isso indica um dos problemas de nosso relacionamento atual com o comércio mundial, como o México e outros, que tiveram tarifas externas muito grandes em muitos, muitos bens. Os Estados Unidos são o país menos protecionista. (...) A outra coisa é que o presidente falou muito sobre reciprocidade; ou seja, se temos um país com grandes barreiras comerciais contra nós, logicamente devemos ter barreiras comerciais similares contra ele. E, se existe um país que tem relativamente poucas barreiras contra nós, devemos ter relativamente poucas contra elas (United States of America, 2017). ${ }^{11}$

No documento Scoring the Trump economic plan: trade, regulatory, \& energy policy impacts, Navarro e Ross (2016) explicam que os acordos comerciais das últimas décadas, com destaque para aqueles que permitiram a entrada da China na OMC em 2001, acabaram catapultando o investimento produtivo para fora dos Estados Unidos, contribuindo para a dispersão da produção offshore. Por fim, a má administração desses acordos, segundo os autores, acabou por ampliar a compra de bens produzidos e comercializados de forma injusta (unfair). Houve críticas também sobre o que identificam como estratégia de Clinton para converter a economia dos

10. Para mais informações, ver: <https://www.nytimes.com/2018/06/11/business/who-is-peter-navarro.html>. 11. No original, "so it's anomalous that the U.S. with its huge trade deficit has a relatively fewer free-trade agreements than do much smaller countries like Mexico. And I think that points out one of the issues with our current relationship with the World Trade, namely Mexico and others have had very big external tariffs on many, many goods. U.S. is the least protectionist country. (...) The other thing about it, the President has talked a lot about reciprocal concept; namely if we have a country that has big trade barriers against us, we should logically have similar trade barriers against them. And if there's a country that has relatively few barriers against us, we should have relatively few against them". 
Estados Unidos numa economia de serviços. ${ }^{12}$ Os empregos no setor de serviços tendem a pagar salários mais baixos. A solução, então, seria promover o setor de manufaturas, desde o ramo têxtil até o aeroespacial, criando as condições para que as corporaçóes investissem em produção no território nacional. No referido documento, os autores deixam claro que é preciso renegociar os acordos da OMC, assim como os outros preferenciais, a fim de corrigir defeitos de concepção que prejudiquem os Estados Unidos, bem como atender a interesses atuais do país. ${ }^{13}$

No mesmo documento, os autores pontuam que o plano econômico de Trump vai muito além da questão tarifária, e que os problemas econômicos do país são de longo prazo e de natureza estrutural, de modo que só poderão ser resolvidos com reformas estruturais. No entendimento dos autores, o plano econômico visa "atacar" os regulamentos que "inibem a contrataçáo", como o Plano de Energia Limpa da Agência de Proteçấo Ambiental (Environmental Protection Agency - EPA), que "força o investimento em energia renovável às custas de carvão e gás natural, aumentando as tarifas de eletricidade" (Navarro e Ross, 2016, p. 7). A moratória do Departamento de Assuntos Internos sobre as licenças de mineração de carvão, que teria reduzido em milhares as vagas de emprego no setor, também é criticada. Com essa nova orientação, pretende-se estimular o setor manufatureiro, considerado um dos principais responsáveis pelo dinamismo da economia do país.

O documento aponta o que os autores chamam de "problema estrutural de longo prazo", ligado à alta taxação, ao excesso de regulamentação e às dificuldades originadas nos deficit comerciais. Esses fatores incluem a manipulação de moeda, o uso igualmente difundido de práticas comerciais mercantilistas pelos principais parceiros comerciais dos Estados Unidos, e acordos comerciais "mal negociados". No tocante à manipulação monetária, os autores pontuam que nem todas as moedas flutuam livremente, impossibilitando a promoção de um comércio equilibrado e justo, sendo a China o principal manipulador. As "trapaças comerciais" chinesas, como eles chamam, incluiriam subsídios ilegais à exportação, roubo de propriedade intelectual,

12. De fato, os Estados Unidos têm um longo histórico de deficit na balança de bens e superavit na balança de serviços (tabela A.3 do apêndice).

13. Outros elementos prioritários seriam a manipulação cambial e a política mercantilista de parceiros comerciais chave. Segundo Navarro e Ross (2016, p. 12, 14 e 20, tradução nossa), para ilustrar o tom do documento, fica claro como reverberam na política comercial de Trump: "Os Estados Unidos ajudaram a negociar e concordam com suas regras comerciais [da OMC], mas, em um sistema de um país, um voto, o país reununciou efetivamente sua soberania a um grupo de países que nem sempre (ou frequentemente) têm os interesses dos Estados Unidos. Embora sejam a maior economia do mundo, têm os mesmos direitos de voto na OMC que países como a Albânia, com economias que representam uma pequena fração da dos norte-americanos"; "Donald Trump entende que a única maneira de corrigir esse tratamento fiscal injusto é que os Estados Unidos usem seu status de maior economia do mundo, maior consumidor do mundo e maior importador do mundo para pressionar a OMC a mudar esse tratamento desigual. Como membro, não haveria muito objetivo para a OMC, mas os ocupantes anteriores da Casa Branca não estavam dispostos a liderar essa questão, apesar de seus significativos impactos negativos"; "Considere que aproximadamente metade do nosso deficit comercial está em apenas seis países: Canadá, China, Alemanha, Japão, México e Coreia do Sul. Se olharmos para as relações bilaterais da América com cada um desses países, a melhoria de nossa balança comercial é claramente alcançável por meio de uma combinação de aumento de exportações e redução de importaçỗes, mas não sem negociações difíceis e inteligentes - uma óbvia qualidade de Trump". 
transferências forçadas de tecnologia e uma dependência generalizada do mercado de trabalho controlado e de paraísos de poluição (Navarro e Ross, 2016).

Outro negociador que devemos destacar é Robert Lighthizer, atual USTR, que compartilha com Trump a intransigência e a desconfiança em relação à China, e o ceticismo em relação ao sistema multilateral de comércio. Lighthizer foi sócio do escritório de advocacia Skadden, onde trabalhou, por mais de trinta anos, com foco no setor de direito comercial internacional. Com graduação e pós-graduação na Universidade de Georgetown, teve um importante papel na administração do presidente Ronald Reagan, sabidamente um duro negociador. Segundo Bryan (2018), Lighthizer ficou conhecido na década de 1980 entre os funcionários japoneses como "o homem-míssil”, depois de pegar as propostas que recebeu da delegação do Japão, fazer um aviāozinho de papel com elas e jogar de volta para os diplomatas japoneses, o que foi entendido como uma verdadeira afronta.

Navarro, Ross e Lighthizer, juntos, compõem o núcleo duro de formulação e execução da política comercial dos Estados Unidos na administração Trump. Além de principais responsáveis pela retirada imediata dos Estados Unidos do TPP, os quatro recorrentemente acusam o que chamam de "defeitos do regime multilateral de comércio", o que, segundo eles, coloca as empresas e os trabalhadores estadunidenses "em desvantagem injusta".

Em linhas gerais, é possível dizer que os quatro são críticos dos acordos regionais, plurilaterais e multilaterais, acusando principalmente a China pelo deficit crônico na balança comercial dos Estados Unidos. A combinação desses elementos tem levado ao fortalecimento dos mecanismos de enforcement estadunidenses, tendo a China como alvo prioritário, e à elevação de barreiras tarifárias em setores específicos, com destaque novamente para aquelas que atingem os chineses. O documento intitulado Trade Policy Agenda de 2019 resume de forma inequívoca a posição central que a China assume para os formuladores norte-americanos: "Os ataques da China à inovação e à propriedade intelectual norte-americanas e de parceiros comerciais dos Estados Unidos desconsideram obrigaçóes trabalhistas e ambientais, e os padrôes científicos" (United States of America, 2019, tradução nossa). ${ }^{14}$

\section{4 "I WANT TARIFFS. BRING ME SOME TARIFFS!": OS PRIMEIROS MOVIMENTOS NO TABULEIRO}

"I want tariffs. Bring me some tariffs", disse Trump para John F. Kelly, após o então chefe de gabinete convocar uma reunião a fim de discutir os planos do governo para investigar a China, acusada de roubo de propriedade intelectual e tecnologia estadunidenses (Swan, 2017). A cena ocorreu em agosto de 2017, no saláo oval

14. No original, "China's attacks on U.S. innovation and intellectual property, and U.S. trade partners disregarding labor and environmental obligations and science-based standards". 
da Casa Branca, e contou com a presença de Lighthizer, Navarro, Cohn, principal consultor econômico, e de Steve Bannon - até aquele momento chiefstrategist da Casa Branca, pouco antes de ser demitido. Fato é que 2018 foi marcado pelo que a imprensa chamou exaustivamente de guerra comercial (trade war).

As complexas negociaçóes para o TPP, concluídas em outubro de 2015, foram, como havia sido prometido durante a campanha eleitoral norte-americana, anuladas pelo presidente Trump por meio de uma medida tomada imediatamente após a sua posse, retirando do Congresso o pedido de ratificação do acordo. A saída do TPP surgiu como símbolo potencialmente enfraquecedor de valores que foram construídos, sob a liderança dos Estados Unidos, desde os acordos de Bretton Woods em 1944 e o final da Segunda Guerra Mundial em 1945. A começar pelo enfraquecimento da própria ideia de livre-comércio, transformada em regime internacional estruturante: político, ideológico e econômico. Foi o que predominou, entre idas e vindas, com distintas interpretaçóes, ao menos durante setenta anos.

No mesmo sentido, a partir de agosto de 2017 , houve a renegociação do NAFTA. A Casa Branca, o Departamento de Comércio, o USTR, além de outras áreas da administração envolvidas, colocam essa negociação em um contexto mais geral, o que significa traçar como objetivo o aumento do índice de regionalização e de nacionalização dos produtos, especificamente do setor automotivo, e a diminuição do deficit dos Estados Unidos em relação a seus dois parceiros, México e Canadá em particular, abaixar suas tarifas para produtos agrícolas norte-americanos. Outro objetivo da administração, por fim não incorporado, era inserir a regra sunset, isto é, o estabelecimento de um prazo de validade do acordo, no caso de cinco anos, ao fim dos quais não haveria renovação automática, devendo, sim, ocorrer uma renegociação formal, sem a qual o tratado seria suspenso.

Em agosto de 2017, o USTR iniciou uma investigação sobre licenciamento "injusto" e políticas "injustas" de propriedade intelectual, usando a seçáo 301 pela primeira vez desde 1997. Durante 2017, a administração Trump conduziu 82 investigaçóes preliminares antidumping $(\mathrm{AD})$ e compensatórias (countervailing duties - CVD), um aumento de $58 \%$ em relação a 2016 - e $28 \%$ a mais que as 64 que o governo de Obama iniciou em 2015, seu ano mais ativo (Levinson-King e Palumbo, 2018).

Em janeiro de 2018 foi a vez de a seção 201 ser usada pela primeira vez desde 2002, quando Trump anunciou sua decisão de fornecer salvaguardas aos fabricantes dos Estados Unidos prejudicados pelas crescentes importaçóes de máquinas de lavar e painéis solares. Além disso, o governo solicitou a abertura de numerosas investigaçôes na $\mathrm{OMC}$, acusando países de práticas comerciais injustas (unfair trade). 
Nesse sentido, a administração tem usado de forma sistemática as medidas de direitos $\mathrm{AD}$ e CVD (gráfico 1).

GRÁFICO 1

Estados Unidos: número de investigações tarifárias (2008-2018)

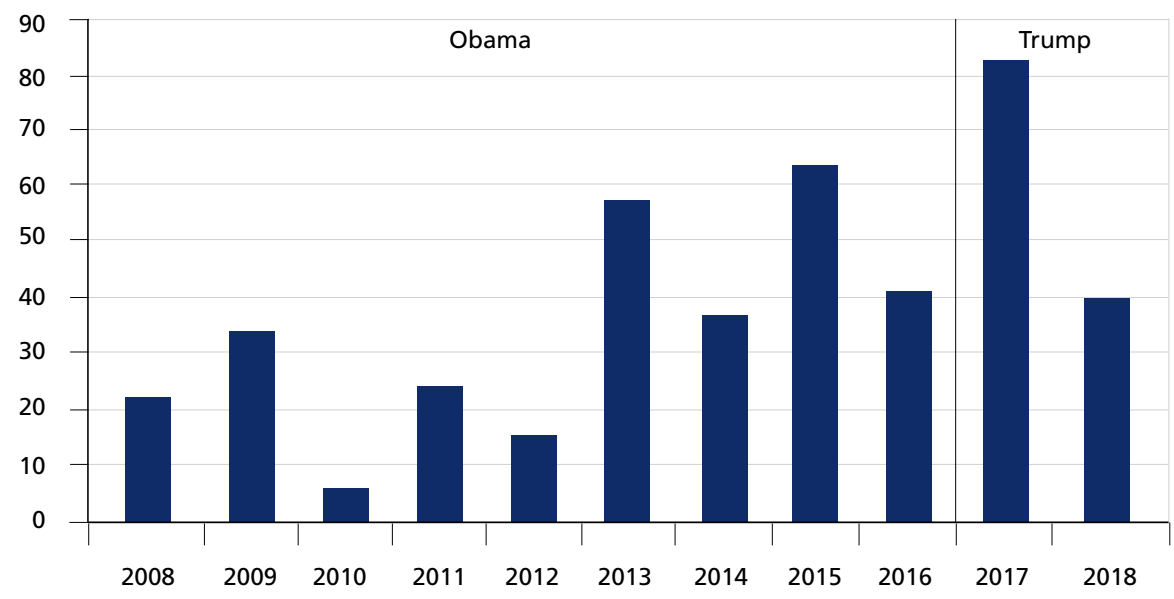

Fonte: Levinson-King e Palumbo (2018).

Houve também uma mudança de protocolo: agora o Departamento de Comércio não aguarda as demandas das empresas afetadas, mas inicia, por conta própria, as investigaçóes. Verifica-se um incentivo ao ativismo administrativo que muda parcialmente as formas como o comércio exterior foi dirigido, ao menos desde 1962, quando o governo John F. Kennedy criou o Special Trade Representative (STR), no contexto da aprovação do Trade Expansion Act. Segundo Levinson-King e Palumbo (2018, tradução nossa), "foi a primeira vez em décadas que o departamento agiu por conta própria em relação às obrigaçôes antidumping ou compensatórias, sem uma reclamação da indústria, e um sinal de mudança na política do departamento sob a nova administração". ${ }^{15}$

Embora o gráfico 1 nos mostre uma redução das investigaçôes em 2018, no segundo ano da administraçáo Trump verifica-se que houve concentração de esforços com apoio de outros mecanismos institucionais. Para Amiti, Redding e Weinstein (2019), podemos falar em seis ondas tarifárias na gestão Trump em 2018, conforme a seguir descrito.

1) Primeira onda: iniciada em janeiro de 2018, trouxe a imposição de tarifas de importação de $30 \%$ em painéis solares, e de $20 \%$ a $50 \%$ em máquinas de lavar. Essas duas categorias de produtos responderam

15. No original, "it was the first time the department acted on its own regarding antidumping or countervailing duties, without a complaint from industry, in decades, and a sign of a shift in the department's policy under the new administration". 
por aproximadamente US\$ 10 bilhôes em importações e criaram um modesto aumento nas tarifas médias dos Estados Unidos (gráfico 2). As tarifas sobre painéis solares terão duração de quatro anos, caindo 5 pontos percentuais (p.p.) a cada ano. Curiosamente, a decisão de Trump atinge negativamente empregos diretamente relacionados a esse setor nos Estados Unidos, como os de estados do sul - Texas, Flórida e Carolina do Sul (Dickinson, 2018). A redução progressiva das tarifas também corresponde a uma forma histórica de negociação comercial de parte dos Estados Unidos. Casa Branca, Departamento de Comércio e USTR agem de forma sabidamente contrária a regras multilaterais de comércio - Acordo Geral de Tarifas e Comércio (General Agreement on Tariffs and Trade - GATT) e, depois de 1994, OMC -, mesmo correndo o risco de ser condenados, com o objetivo de ganhar tempo para alcançar maior competitividade ou enfraquecer a capacidade produtiva ou mercadológica do parceiro com o qual está em litígio comercial (Jackson, Davey e Sykes, 2002). Do mesmo modo, a aplicação unilateral de sanções - mesmo a terceiros países, como previsto pela Lei Helms-Burton, de 1996, ou, em 2019, no caso das sançóes ao Irã - é entendida pelo direito internacional como violação das decisôes da OMC, especificamente do Tratado de Marrakesh, de 1994. A administração age baseada na lógica de que eventuais condenaçôes sejam compensadas pelos benefícios advindos.

\section{GRÁFICO 2}

\section{Estados Unidos: ondas tarifárias (2018)}

(Em \%)

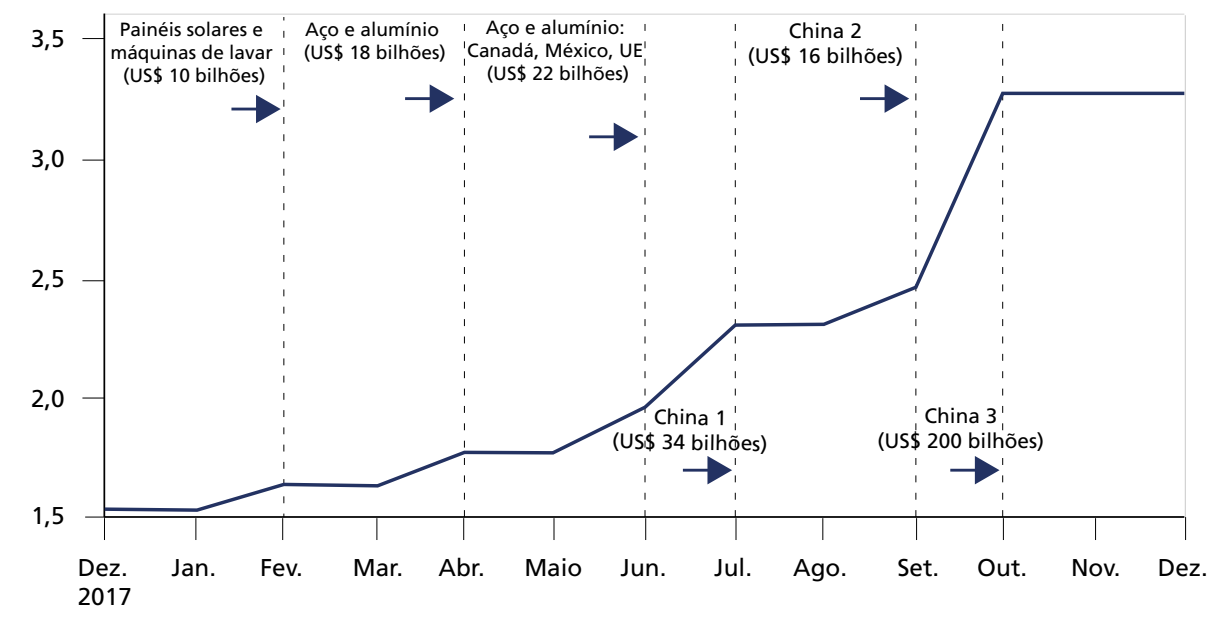

Fonte: Amiti, Redding e Weinstein (2019). 
2) Segunda onda: iniciada a partir de março de 2018 , marcou a implementação de $10 \%$ de tarifas na importação de alumínio e $25 \%$ nas importaçóes de aço, com impacto estimado em US\$ 18 bilhóes (Amiti, Redding e Weinstein, 2019). Segundo York (2018), as recomendaçóes para impor essas tarifas vieram do Departamento de Comércio, após uma revisão das importaçóes de aço e de alumínio, solicitada pelo presidente Trump, alegando ameaças à segurança nacional. Para isso, recorreu-se à seção 232 da Lei de Expansão do Comércio (Trade Expansion Act), de 1962. Esse dispositivo legal prevê que o Departamento de Comércio determine o impacto de certas importaçóes sobre a segurança nacional do país. $\mathrm{O}$ aço, utilizado na indústria militar, é insumo básico para empresas com gama de produtos muito diversificados. Por isso, historicamente, a queda da produção interna frente à concorrência internacional é considerada sinal de risco à indústria nacional e de maior vulnerabilidade do país.

Ainda que contenciosos sobre o aço tenham surgido inúmeras vezes desde os anos 1960 e atingido diferentes países, como Reino Unido, Alemanha, Japão, México, Brasil, China e República da Coreia, o uso da seção 232 foi parcimonioso. Nos últimos 54 anos, foram apenas 26 ocorrências, das quais cinco terminaram em resolução presidencial e apenas uma produziu efeito concreto.

Como Trump foi eleito com amplo apoio do cinturão da ferrugem (rust belt), prometendo trazer novos empregos a esses setores, existe uma preocupaçáo adicional sobre a inclinação de sua equipe para que essa medida seja realmente posta em prática. A intenção do governo seria principalmente conter as exportaçóes chinesas, já que a China é o maior exportador de aço do mundo, ainda que não seja o principal exportador para os Estados Unidos. A utilização de recursos da legislação interna, tema amplamente analisado pela literatura, serviu como elemento fortalecedor do poder de barganha, impondo às contrapartes barreiras quantitativas, traduzidas na forma de restriçôes voluntárias.

3) Terceira onda: essa é na verdade uma ampliação da onda anterior marcada pela inclusão, em junho de 2018, de países como o Canadá e o México, bem como a UE, entre os sujeitos à taxação, atingindo US\$ 22 bilhóes em tarifas (Amiti, Redding e Weinstein, 2019). Essa onda surgiu no contexto das renegociaçóes do NAFTA, ${ }^{16}$ encabeçadas pelo USTR Lighthizer, que afirmou: "Queremos um acordo justo para o México e justo para o Canadá, mas que mantenha a integridade dos programas

16. Este tipo de negociação paralela é muito comum na história da política comercial dos Estados Unidos (Vigevani, Mendonça e Lima, 2018). 
de aço e alumínio do presidente, que tiveram muito sucesso nos Estados Unidos" (Dhue, 2018, tradução nossa). ${ }^{17}$

4) Quarta onda: em 15 de julho de 2018, o USTR divulgou uma lista ${ }^{18}$ de produtos importados da China que passariam a ser objeto de tarifas adicionais como parte da resposta dos Estados Unidos ao que consideram "práticas comerciais desleais da China relacionadas à transferência forçada de tecnologia e propriedade intelectual norte-americanas" (United States of America, 2018d). As tarifas de $25 \%$ tiveram um impacto inicial estimado de US\$ 34 bilhóes nas importações chinesas (Amiti, Redding e Weinstein, 2019), atacando pontos do plano chinês intitulado Made in China 2025, considerado desleal pelos Estados Unidos. A China reagiu imediatamente e anunciou uma política retaliatória sobre US\$ 34 bilhôes em importações norte-americanas, incluindo produtos agrícolas (Cheng, 2018). No que diz respeito aos Estados Unidos, a medida foi amparada pela seção 301 da própria legislação de comércio, do Trade Act de 1974, modificada pelo Omnibus Trade and Competitiveness Act de 1988. Segundo o representante de Comércio dos Estados Unidos, Robert Lighthizer,

devemos empreender fortes açóes defensivas para proteger a liderança norte-americana em tecnologia e inovação contra a ameaça sem precedentes representada pelo roubo de propriedade intelectual da China, a transferência forçada da tecnologia norte-americana e seus ataques cibernéticos às redes de computadores (...) trabalhando agressivamente para minar as indústrias de alta tecnologia da América e nossa liderança econômica por meio de práticas comerciais desleais e políticas industriais como o Made in China 2025. Tecnologia e inovação são os maiores ativos econômicos da América e o presidente Trump reconhece, com razão, que, se queremos que nosso país tenha um futuro próspero, devemos tomar uma posição agora para defender o comércio justo e proteger a competitividade norte-americana (United States of America, 2018d, tradução nossa). ${ }^{19}$

5) Quinta onda: em agosto de 2018, os Estados Unidos impuseram à China uma segunda parcela de $25 \%$ sobre outros US\$ 16 bilhóes

17. No original, "We want an agreement that is fair to Mexico and fair to Canada but maintains the integrity of the president's steel and aluminum programs which have been very successful for the U.S.".

18. Essa lista de produtos consiste em dois conjuntos de linhas tarifárias dos Estados Unidos. O primeiro conjunto contém 818 linhas das 1.333 originais incluídas na lista proposta, publicada em 6 de abril. 0 segundo conjunto contém 284 linhas tarifárias propostas identificadas pelo Comitê Interinstitucional da seção 301 como beneficiando as políticas industriais chinesas, incluindo a política industrial Made in China 2025 (United States of America, 2018d).

19. No original, "we must take strong defensive actions to protect America's leadership in technology and innovation against the unprecedented threat posed by China's theft of our intellectual property, the forced transfer of American technology, and its cyber attacks on our computer networks (...) China's government is aggressively working to undermine America's high-tech industries and our economic leadership through unfair trade practices and industrial policies like "Made in China 2025". Technology and innovation are America's greatest economic assets and President Trump rightfully recognizes that if we want our country to have a prosperous future, we must take a stand now to uphold fair trade and protect American competitiveness". 
(Amiti, Redding e Weinstein, 2019), usando para isso novamente a seção 301. Foram acrescentados 279 novos produtos à lista da onda anterior. ${ }^{20}$ Segundo Lighthizer, as alterações foram feitas após o próprio USTR e o comitê interagências que administra a utilização da seção 301 terem solicitado e recebido comentários por escrito e testemunhos durante uma audiência pública de dois dias em julho de 2018 (United States of America, 2018b). As investigaçóes revelaram que a China:

a) usa requisitos de joint venture, restriçóes de investimento estrangeiro e processos de revisão e licenciamento administrativos para exigir ou pressionar a transferência de tecnologia de empresas norte-americanas;

b) priva as empresas estadunidenses da capacidade de estabelecer termos baseados no mercado em licenciamento e outras negociaçóes relacionadas à tecnologia;

c) dirige e facilita injustamente o investimento sistemático e a aquisição de empresas e ativos dos Estados Unidos para gerar transferência de tecnologia em larga escala; e

d) realiza e apoia invasóes cibernéticas nas redes comerciais de computadores dos Estados Unidos para obter acesso não autorizado a informaçôes comerciais lucratrivas (United States of America, 2018b, tradução nossa). ${ }^{21}$

6) Sexta onda: em 18 de setembro de 2018, os Estados Unidos impuseram um terceiro pacote de tarifas com impacto adicional de US $\$ 200$ bilhóes nas importaçóes chinesas. As tarifas, inicialmente de 10\%, incluídas nessa última onda estavam programadas para aumentar seu valor em mais 15\% em janeiro de 2019, até que os presidentes Donald Trump e $\mathrm{Xi}$ Jinping anunciassem uma trégua temporária em dezembro, durante a reunião do Grupo dos Vinte (G20), realizada em Buenos Aires (Amiti, Redding e Weinstein, 2019). Depois de novas consultas empreendidas pelo USTR e pelo comitê interagências, foram adicionados às listas anteriores mais 5.745 produtos. $^{22}$ Os argumentos para justificar a ampliaçấo das tarifas eram exatamente os mesmos das duas ondas anteriores (United States of America, 2018c).

20. Disponivel em: <https://bit.ly/2LX8R6x>.

21. No original, "a) China uses joint venture requirements, foreign investment restrictions, and administrative review and licensing processes to require or pressure technology transfer from U.S. companies; b) China deprives U.S. companies of the ability to set market-based terms in licensing and other technology-related negotiations; c) China directs and unfairly facilitates the systematic investment in, and acquisition of, U.S. companies and assets to generate large-scale technology transfer; e d) China conducts and supports cyber intrusions into U.S. commercial computer networks to gain unauthorized access to commercially valuable business information".

22. Disponivel em: <https://bit.ly/2PTc1pm>. 


\section{5 "AMERICA FIRST BUT NOT ALONE"}

Em reação às inúmeras ondas tarifárias da administração Trump, o Ministério das Finanças da China publicou quatro listas de bens a ser atingidos com tarifas adicionais de $25 \%, 20 \%, 10 \%$ e 5\%, respectivamente. A primeira lista, cuja tarifa adicional é de $25 \%$, cobre aproximadamente 2.500 artigos, incluindo alimentos, produtos químicos, têxteis e siderúrgicos, eletrodomésticos e móveis (Siripurapu, 2018). Os agricultores norte-americanos, principalmente os de soja, foram prejudicados com essa retaliação e têm se mobilizado a fim de reverter a situação. Esses produtores tiveram relevância na eleição de Trump. Por meio do Departamento de Agricultura, o governo, que tenta reverter o prejuízo, anunciou uma ajuda de US\$ 12 bilhóes para os afetados por essas tarifas (United States of America, 2018a).

Relativamente ao aço, de acordo com IHS Global Atlas, a China não se encontra entre os dez principais fornecedores dos Estados Unidos. O Canadá é o principal fornecedor, representando $20 \%$ das importações, seguido por Brasil com $12 \%$, México com $11 \%$, Coreia do Sul com 10\% e Rússia com $8 \%$ (United States of America, 2018e). O anúncio do novo nível de tarifas foi recebido negativamente e criticado não apenas pela China, que afirmou que as taxas são uma grave violação às regras da OMC, mas também por Canadá e UE, cujos governos ameaçaram retaliaçóes.

No dia 2 de dezembro de 2018, por ocasião da reunião do G20, em Buenos Aires, Xi Jinping e Trump puderam alcançar um acordo provisório. A tensão comercial entre China e Estados Unidos parece ter arrefecido. Na ocasiáo, Trump anunciou uma quarentena até $1^{\circ}$ de março de 2019, prometendo dobrar as tarifas, caso nenhum acordo fosse firmado até lá. $\mathrm{O}$ anúncio foi seguido de uma redução das tarifas chinesas no dia 14 de dezembro de 2018. Em 30 de janeiro de 2019, a China e os Estados Unidos retomaram as negociaçóes em Washington. A representação norte-americana foi chefiada por Robert Lighthizer, considerado mais moderado do que Peter Navarro e Wilbur Ross em relação à China. As tratativas prosseguiram em 11 de fevereiro, em Pequim. A busca da pressão sem rupturas irreversíveis parecia ser o tom: "se pudermos fazer o acordo, seria uma honra remover as tarifas", disse Trump (Sebenius e Mayeda, 2019, tradução nossa). ${ }^{23}$ Em março de 2019, Trump anunciou a extensão da quarentena, enquanto fazia pressão para a assinatura de um acordo.

Esse acompanhamento do processo negociador certamente não oferece a possibilidade de previsão dos desdobramentos do trumpismo comercial nos próximos anos, mas consolida a ideia de estarem em curso mudanças importantes no comércio internacional. Essas mudanças, entretanto, não apontam na direção

23. No original, "if we can make the deal it would be my honor to remove the tariffs". 
de transformaçóes radicais no sistema multilateral e liberal construído a partir de 1944. Podemos sugerir, mesmo provisoriamente, que estamos diante de uma forte radicalização do próprio sistema: o trumpismo detém as rédeas do poder e os mecanismos de Fair Trade que a legislação interna dos Estados Unidos e parte dos regimes internacionais construídos lhes permitem. Passos além dos regimes estão sendo experimentados, mas sem cortar as amarras de forma irreversível. A percepção de parte de alguns parceiros parece ser essa. Segundo Yan Xuetong, da Universidade de Tsinghua, em entrevista ao China Daily, há elementos para pensar que a posição norte-americana vai se tornando mais dura, evoluindo de posiçóes liberais para mais impositivas, transladando-se da busca do convencimento para a imposição. Segundo Xuetong,

na superfície, o governo Trump alega que deseja equilibrar o deficit comercial, mas meu entendimento é que o objetivo real é recuperar a sua influência dominante, e agora eles querem abandonar a ordem comercial baseada na OMC, originalmente criada pelos Estados Unidos. Mas, para usar suas palavras, a OMC é "dominada pela China, não pelos Estados Unidos”. Então, querem sair da $\mathrm{OMC}$ e restabelecer uma ordem favorável a eles. (...) O poder da América está em declínio, enquanto o governo Trump não está fornecendo autoridade suficiente para ganhar a confiança de outras pessoas nos Estados Unidos e complementar seu poder decrescente. Assim, é muito difícil para eles liderar de fato ou reconstruir uma nova ordem mundial, que requer mais poder do que interromper a atual (Yu, 2018, tradução nossa).

Segundo o estudo produzido pelo World Bank Group, de março de 2019 (Fajgelbaum et al., 2019), o resultado das retaliaçóes cruzadas no ano de 2018 é irrisório, 0,04\% do PIB (gross domestic product-GDP) dos Estados Unidos, ou US\$ 7,8 bilhôes de perdas brutas para a economia norte-americana. Ao mesmo tempo, tentando interpretar estrategicamente o significado da guerra comercial e do neomercantilismo, é importante entender as consequências do ponto de vista do interesse norte-americano, ao menos na perspectiva da administração Trump: o deficit estrutural mostrou baixa elasticidade, não diminuído efetivamente (tabela A.3 do apêndice). O que deve levar à busca de mais razóes e componentes.

A administração Trump pode colocar os Estados Unidos em primeiro lugar, mas não sem a reação de seus principais parceiros externos e de atores internos. A tabela A.1 do apêndice mostra o peso da China nas importaçóes norte-americanas: em 2017, foi responsável por 21,85\% das importações do país, contra 13,18\% do México, e 12,71\% do Canadá. Já no que diz respeito às exportaçôes, a China recebeu $8,40 \%$ das exportaçóes norte-americanas, o México $15,74 \%$, e o Canadá 18,26\%. Já a tabela A.2 apresenta um quadro mais fiel dos resultados práticos da política tarifária de Donald Trump. A China manteve o peso dentro das importaçôes norte-americanas, mesmo depois de inúmeras ondas tarifárias. Houve, entretanto, uma queda importante entre novembro de 2017 
e março de 2018 , de 23,44\% para 18,60\%. Em setembro de 2018, a China recuperou seu peso normal, atingindo $23,96 \%$. Embora ciclos sazonais naturais do comércio internacional nos ajudem a entender parte dessas oscilaçôes, não se pode negar que a política tarifária da administração Trump teve o seu papel. Se isso é verdade, a rápida recuperação do peso chinês no mês de setembro de 2018 no comércio bilateral demonstra a capacidade de acomodação dos fluxos de comércio dos dois países. Como a pesquisa do World Bank Group indica, a inelasticidade de curto prazo é grande.

A política tarifária de Donald Trump, além de não reduzir o deficit na balança comercial dos Estados Unidos, gera custos adicionais importantes para o consumidor estadunidense, como demonstra o estudo de Amiti, Redding e Weinstein (2019, p. 22, tradução nossa). ${ }^{24}$

Estima-se que o custo cumulativo de bem-estar do porte bruto (reduçáo na renda real) das tarifas dos Estados Unidos seja de aproximadamente US\$ 6,9 bilhóes durante os primeiros onze meses de 2018, com um custo adicional de US\$ 12,3 bilhôes para consumidores e importadores domésticos na forma de receita tarifária transferida para o governo. Somente os custos com assistência social atingiram US\$1,4 bilhăo por mês até novembro de 2018. A guerra comercial também causou ajustes drásticos nas cadeias de suprimentos internacionais, pois cerca de US\$165 bilhôes em comércio (US\$ 136 bilhōes em importaçôes e US\$ 29 bilhões em exportaçôes) foram perdidos ou redirecionados para evitar as tarifas. Constatamos que as tarifas norte-americanas foram quase completamente repassadas para os preços domésticos, de modo que toda a incidência das tarifas recaiu nos consumidores e importadores domésticos, sem impacto até agora nos preços recebidos pelos exportadores estrangeiros. Também descobrimos que os produtores responderam à redução da concorrência de importação aumentando seus preços.

Outro estudo aponta na mesma direção. Segundo Fajgelbaum et al. (2019), "as tarifas de importação aumentaram de 2,6\% para 17\% em 12.007 produtos (67\% dos produtos importados), cobrindo US\$ 303 bilhóes (12,6\%) das importaçóes anuais dos Estados Unidos em 2017”. Já as retaliaçōes dos parceiros comerciais dos Estados Unidos, segundo esses autores, aumentaram as tarifas de 6,6\% para $23 \%$ em 2.931 produtos de exportação (34\% dos produtos exportados), cobrindo US\$ 96 bilhões (6,2\%) das exportaçóes anuais dos Estados Unidos em 2017. Se houve ganhos e perdas, o resultado líquido para a economia norte-americana é pífio.

24. No original, "we estimate the cumulative deadweight welfare cost (reduction in real income) from the U.S. tariffs to be around $\$ 6.9$ billion during the first 11 months of 2018, with an additional cost of $\$ 12.3$ billion to domestic consumers and importers in the form of tariff revenue transferred to the government. The deadweight welfare costs alone reached \$1.4 billion per month by November of 2018. The trade war also caused dramatic adjustments in international supply chains, as approximately $\$ 165$ billion dollars of trade $\$ 136$ billion of imports and $\$ 29$ billion of exports) is lost or redirected in order to avoid the tariffs. We find that the U.S. tariffs were almost completely passed through into U.S. domestic prices, so that the entire incidence of the tariffs fell on domestic consumers and importers up to now, with no impact so far on the prices received by foreign exporters. We also find that U.S. producers responded to reduced import competition by raising their prices". 
Estimamos uma perda anual para os Estados Unidos de US\$ 68,8 bilhóes devido a preços de importaçáo mais altos. Usando uma estrutura de equilíbrio geral e as elasticidades estimadas, calculamos ganhos de US \$21,6 bilhôes com os preços mais altos recebidos pelos produtores norte-americanos. A redistribuição dos compradores de mercadorias estrangeiras para os produtores norte-americanos e o governo prevê um efeito negativo de US $\$ 7,8$ bilhóes anualmente para a economia $(0,04 \%$ do PIB). Nossos cálculos mostram que, na ausência de retaliaçóes, o impacto agregado na economia seria insignificante, com um terço desse valor (Fajgelbaum et al., 2019, p. 30 , tradução nossa). ${ }^{25}$

Outro ponto importante a se observar diz respeito ao jogo político doméstico. Mesmo diante de inúmeras retaliaçóes cruzadas e do esforço para concluir algum acordo com a China, Peter Navarro continua defendendo tarifas, barreiras comerciais e cotas com o objetivo de sanar o deficit comercial, desencorajar importaçóes e estimular o desenvolvimento da indústria nacional (Ball, 2018). Navarro afirma também que a China já teve sua chance de mudar, e que precisa sentir as dificuldades que as tarifas trazem para sua economia, a fim de, assim, ceder às exigências dos Estados Unidos, como a abertura total do mercado para empresas norte-americanas, e não forçar a entrega de tecnologia de empresas norte-americanas para o país.

Diante dessa dura posição de Navarro e do ativismo de Wilbur Ross, a correlação de forças do núcleo executivo da formulação da política comercial dos Estados Unidos parece estar se movimentando. Robert Lighthizer ganha espaço dentro da condução da política comercial dos Estados Unidos com a China, principalmente depois do que Trump considerou uma bem-sucedida renegociação do NAFTA. Tudo indica que, na segunda metade de sua administração, 2019 e 2020, o USTR ganhará espaço na condução da agenda comercial, sobretudo se a lógica política e estratégica se fortalecer. De fato, os ganhos econômicos e os benefícios dos acordos e das relaçôes comerciais parecem pequenos. Para a renegociação do NAFTA e o novo Acordo Estados Unidos-México-Canadá (United States-Mexico-Canada Agreement - USMCA), segundo estudo do Fundo Monetário Internacional (FMI) (Burfisher, Lambert e Matheson, 2019), o balanço é de pequenos resultados positivos. Resultados análogos ou até melhores, sempre segundo esse estudo, poderiam ser alcançados se fossem simplesmente eliminadas, pelos Estados Unidos, as tarifas adicionais para aço e alumínio; e, da parte do México e do Canadá, as tarifas retaliatórias.

O Partido Republicano, histórico defensor do livre-comércio, tem se desviado dessa agenda, em grande medida influenciado pela Casa Branca. Já o Partido

25. No original, "we estimate an annual loss for the U.S. of $\$ 68.8$ billion due to higher import prices. Using a general equilibrium framework and the estimated elasticities, we compute gains of $\$ 21.6$ billion from higher prices received by US producers. The redistribution from buyers of foreign goods to U.S. producers and the government nets out to a negative effect of $\$ 7.8$ billion on annual basis for the U.S. economy $(0.04 \%$ of GDP). Our computations show that, in the absence of retaliations, the aggregate impact on the U.S. economy would have been negligible, at one third of that value". 
Democrata, talvez por conta de sua proximidade com os sindicatos, é um histórico crítico do livre-comércio, mas também tem mudado de postura em alguns casos nos últimos anos. Com a retomada do controle do partido na Câmara, a posição democrata é incerta e tende a ser decisiva nos últimos dois anos da administração Trump. Vimos que o núcleo da condução da política comercial dos Estados Unidos durante os dois primeiros anos desse governo foi um Executivo que utiliza intensamente o protecionismo, afastando-se do padrão histórico do país, que teve nesse poder o eixo das políticas liberais, antiprotecionistas, ainda que com exceçóes pontuais.

Questionado sobre a escalada tarifária imposta pela administração Trump, o senador Chuck Schumer, líder do Partido Democrata no Senado, afirmou que "A China latirá de volta. Mas eles precisam de nós mais do que precisamos deles o presidente Trump está certo sobre isso -, e devemos ser fortes. Então pensei que o que ele fez na China está certo" (Sanchez, 2018b, tradução nossa). ${ }^{26}$ A carta, enviada a Donald Trump, e escrita por Schumer e pelos senadores democratas Ron Wyden e Sharrod Brown, em novembro de 2018, é sintomática: pede-se que o presidente "jogue duro com a China” até que mudanças estruturais ocorram no país. ${ }^{27}$ Brown, senador por Ohio, também é autor de um livro, publicado em 2005, chamado Myths of free trade: why american trade policy has failed, em que busca desfazer o que chama de "sete mitos" da política comercial dos Estados Unidos - entre eles o de que os norte-americanos acreditam no livre-comércio; que o NAFTA foi um sucesso; e que o livre-comércio é parte de uma grande tradição estadunidense (Brown, 2004).

A eleição de Donald Trump parece ser forte evidência do enfraquecimento do discurso liberal e da defesa da globalização entre o eleitorado norte-americano. A queda do desemprego nos Estados Unidos, entretanto, tem contribuído para uma visão mais positiva do comércio internacional no país (Jones, 2018). As pesquisas de opiniáo conduzidas pela National Broadcasting Company (NBC) e pelo Wall Street Journal, entre 2016 e 2018, mostram um crescimento da opinião positiva sobre o comércio internacional e, consequentemente, um enfraquecimento do discurso neomercantilista entre os eleitores. ${ }^{28}$ Perguntados sobre o papel do livre-comércio na economia do país, $43 \%$ dos entrevistados responderam que ajudou, e 34\% afirmaram que prejudicou, revertendo assim um quadro atípico que contribuiu para a eleição de Trump.

26. No original, "China will bark back. But they need us more than we need them - President Trump is right about that - and we should be strong. So I thought what he did on China is right".

27. Disponível em: <https://bit.ly/2T2Al5t>.

28. Enquanto em 2016 a visão negativa do comércio atingiu o seu pico, com 43\%, esse número caiu em 2017 para $34 \%$, e em 2018 para 23\%. Já a visão positiva do comércio atingiu 27\% em 2016, 43\% em 2017 e $50 \%$ em 2018 , patamar mais elevado de toda a série histórica. Informação disponível em: <https://bit.ly/2YxWu6s >. 


\section{CONSIDERAÇÕES FINAIS: UMA (NEM TÃO) NOVA POLÍTICA COMERCIAL?}

Diante desse quadro, afirma-se que a política comercial dos Estados Unidos nos oferece uma reflexão do tipo American first but not alone. Existe oposição (mas também apoio) dentro do próprio país, e existe oposição fora do país. Resta saber se a política unilateral e agressiva da administraçáo Trump terá força suficiente para ultrapassar as duas barreiras. Ademais, parece ser inegável que o trumpismo traz, sim, elementos novos para a condução da política comercial dos Estados Unidos. Essas políticas, entretanto, sofrem outros constrangimentos estruturais.

Em primeiro lugar, a política comercial dos Estados Unidos não ocorre sem resistência de outros países. A China e a UE, principalmente, se movimentam para coibir e retaliar as ações norte-americanas. As retaliaçôes, deve-se lembrar, são calculadas para atingir regióes sensíveis do jogo político norte-americano, o que torna a continuidade da guerra comercial uma incógnita, explicando-se assim algumas das oscilaçôes da administração. Ao não haver um núcleo estruturado impulsionador dos grandes acordos e da globalização vinculado às grandes corporaçóes, diversas delas ligadas à alta tecnologia, muitos dos cálculos serão determinados pela aproximação das eleições de 2020. Cálculos políticos das forças que sustentam a administração podem avaliar que a estratégia é política e eleitoralmente favorável a eles: ativistas republicanos e candidatos aderem à lógica do presidente, rompendo com a histórica defesa que faziam do livre-comércio. Um estudo feito por economistas liberais norte-americanos afirma que boa parte dos setores protegidos pela política tarifária da administração Trump encontrava-se em regiōes competitivas eleitoralmente (swing regions), enquanto as retaliaçóes externas afetavam redutos republicanos que concentram a maior parte dos custos da guerra comercial (Fajgelbaum et al., 2019, p. 30).

Em segundo lugar, há limites internos para uma revisão drástica da política comercial dos Estados Unidos. É preciso considerar o papel dos grupos organizados, da opinião pública e do Congresso nessa equação. Parte dos pesquisadores e dos intelectuais universitários também parece reagir, desenvolvendo estudos que sinalizam os limites da política comercialista, como mostram Fajgelbaum et al. (2019) e Amiti, Redding e Weinstein (2019). Esse contexto de choque entre os que têm percepção de derrota ou sentem-se ameaçados pela globalizaçáo, responsáveis pela eleição de Trump, e os afetados pela guerra comercial, em sua maioria em redutos republicanos, tende a ser uma questão relevante para a continuidade da política a curto prazo, considerando o horizonte das eleiçóes norte-americanas de 2020.

A política de Trump sob o mote America First deve ser entendida como um subproduto do conceito de fairness, materializado em mecanismos de enforcement. Essa característica é importante pois permite um discurso agressivo, típico do trumpismo, 
sem ter necessariamente que cumprir as promessas na íntegra. E isso nem sempre é um problema do ponto de vista eleitoral: o presidente pode convencer seu eleitorado de que políticas revisionistas mais agressivas foram "contidas" pelo establishment ou pelo "sistema". Enquanto parte do senso comum parece pressupor que o trumpismo é uma grave ameaça às instituiçóes de livre-comércio nos Estados Unidos, concluímos o contrário: ao que tudo indica, é possível inferir que o trumpismo na área comercial só existe graças, em larga medida, à existência desses mecanismos de contenção institucional que acabaram produzindo um comportamento "transformista", de adaptação, das grandes corporaçôes. Considerando o legado que Trump herdou, entendemos que esse tipo de fairness tem sido institucionalizado nos Estados Unidos por meio de mecanismos de enforcement, o que pode afetar grandes parceiros comerciais, com possíveis desdobramentos para o Brasil.

Paradoxalmente, a guerra comercial com a China fez surgir uma nova proposta no sentido de que os Estados Unidos voltassem a pensar no TPP como uma alternativa comercial viável. Os onze países que compunham o TPP celebraram um novo tratado chamado Acordo Abrangente e Progressivo para a Parceria Transpacífica (Comprehensive and Progressive Agreement for TPP - CPTPP). Além disso, esses países, segundo Behsudi (2017), estariam envolvidos em outros 27 acordos de livre-comércio entre eles, e com a China e a UE. Grupos dos Estados Unidos - Freedom Partners, Americans for Prosperity e The LIBRE Initiative, por exemplo - declararam apoio para que o país renegocie o TPP. Mesmo que essas pressões não se concretizem em recuos da atual administração, isso mostra como o debate na sociedade norte-americana existe e tem força.

Ainda que o foco do nosso texto tenha sido o comércio, outras questôes explicam boa parte das pressóes relativas ao tema. $\mathrm{Na}$ introdução, consideramos o papel das relaçôes estratégicas. Questão importante, sobretudo para a China, na medida em que, depois do $19^{\circ}$ Congresso do Partido Comunista, em outubro de 2017, o tema da construçáo de novos paradigmas tecnológicos e do poder estratégico se colocaram como objetivos em construção. A demonstração da baixa elasticidade das relaçóes comerciais e econômicas, em particular das financeiras e de investimentos, mesmo considerando que o incentivo à realocação de recursos possa produzir algum resultado, sugere que outros fatores são centrais na guerra comercial. Não apenas no tocante à China, mas para os países que possam ter poder competitivo, ao menos setorialmente.

Provavelmente, trata-se de enfrentar, em diferentes campos, as grandes questóes do mundo contemporâneo. E isso explica o razoável apoio existente a essa política da administração Trump, não sendo necessariamente um apoio eleitoral futuro. Segundo Atkinson e Foote (2019, p. 50, tradução nossa): 
os dados apresentados aqui são uma indicação clara de que a China está progredindo mais rapidamente nas indústrias de inovação e tecnologia avançada do que os Estados Unidos. Não há razão para acreditar que esse progresso fracasse na próxima década, principalmente se a China continuar com seu compromisso com o Made in China 2025, e os países avançados não conseguirem recuar com sucesso contra as políticas e práticas mercantilistas da inovação chinesa. Mas, para garantir a liderança contínua, os Estados Unidos devem fazer mais do que unir-se a aliados para convencer a China a seguir as regras, deve implementar sua própria estratégia nacional robusta de inovação e competitividade. No início dos anos 1960, em resposta ao Sputnik, o governo tomou medidas imediatas para criar uma capacidade significativa de tecnologia avançada civil e militar, investindo mais em P\&D do que o resto das empresas e governos do mundo combinado - e valeu a pena para os Estados Unidos pois se tornaram a economia dominante em tecnologia por meio século. Se os Estados Unidos quiserem manter esse manto de liderança e usufruir dos vastos benefícios advindos da vitória nas indústrias de tecnologia avançada, será necessária uma grande reforma nas políticas nacionais. ${ }^{29}$

Com essa longa referência, podemos concluir a análise da política comercial da administração Trump, consolidando a ideia que provavelmente observaremos maior uso de instrumentos duros, sem necessariamente romper a institucionalidade do comércio, construída internacional e nacionalmente nos últimos setenta anos.

\section{REFERÊNCIAS}

AMITI, M.; REDDING, S. J.; WEINSTEIN, D. The impact of the 2018 trade war on U.S. prices and welfare. National Bureau of Economic Research, Cambridge, United States, p. 1-41, Mar. 2019. (Working Paper, n. 25672).

ATKINSON, R. D.; FOOTE, C. Is China catching up to the United States in innovation? Information Technology and Innovation Foundation, Apr. 2019. Disponível em: <https://bit.ly/2YBDe41>. Acesso em: 30 abr. 2019.

BALL, M. Peter Navarro used to be a democrat. Now he's the mastermind behind Trump's trade war. Time, 23 Aug. 2018. Disponível em: <https://bit.ly/2K5VOwO>.

BEHSUDI, A. Trump's trade pullout roils rural America. Politico Magazine, 7 Aug. 2017. Disponível em: <http://bit.do/faM67>.

29. No original, "the data presented here is a clear indication China is making more rapid progress in innovation and advanced technology industries than the United States. There is no reason to believe this progress will slack over the next decade, particularly if China continues its commitment to Made in China 2025, and advanced nations fail to successfully push back against Chinese innovation mercantilist practices and policies. But to ensure continued U.S. leadership, the United States must do more than join with allies to convince China to play by the rules, it must put in place its own robust national innovation and competitiveness strategy. In the early 1960s, in response to Sputnik, the U.S. government took prompt action to build a significant civilian and military advanced technology capability, investing more in $R \& D$ than the rest of the world's businesses and governments combined - and it paid off in spades, leading to the United States becoming the dominant technology economy for a half century. If the United States wants to retain that mantle of leadership, and enjoy the vast benefits that come from winning in advanced technology industries, it will need a major overhaul of national policies". 
BROWN, S. Myths of free trade: why american trade policy has failed. New York: New Press, 2004.

BRYAN, B. Trump's newest pick to lead the trade fight against China reportedly took the Chinese by surprise and could be bad news for a deal. Business Insider, 4 Dec. 2018. Disponível em: <https://bit.ly/315HNVK>.

BURFISHER, M. E.; LAMBERT, F.; MATHESON, T. NAFTA to USMCA: what is gained? IMF Working Paper, n. 19/73, March 2019. Disponível em: $<$ https://ssrn.com/abstract=3377474>.

CHENG, E. China announces retaliatory tariffs on $\$ 34$ billion worth of US goods, including agriculture products. CNBC, 15 June 2018. Disponível em: $<$ https://cnb.cx/2HRXDJy>.

DESTLER, I. M. American trade politics: system under stress. Washington D.C.: Institute for International Economics, 2005.

DHUE, S. Steel and aluminum tariffs remain a headache despite Trump's trade deal with Mexico and Canada. CNBC, 30 Nov. 2018. Disponível em: $<$ https://cnb.cx/2AJcSDe>.

DICKINSON, T. Trump's tax on solar power: here's what you need to know. Rolling Stone, 24 Jan. 2018. Disponível em: <https://bit.ly/2YgFlyS>.

FAJGELBAUM, P. D. et al. The return to protectionism. National Bureau of Economic Research, Cambridge, United States, p. 1-70, Mar. 2019. (Working Paper, n. 25638).

HELMORE, E. Peter Navarro; the economist shaping Trump's economic thinking. The Guardian, 11 Mar. 2018. Disponível em: <https://bit.ly/2Hv6cdk>.

JACKSON, J. H.; DAVEY, W. J.; SYKES, A. O. Legal problems of international economic relations: cases, materials and text on the national and international regulation of transnational economic relations. St. Paul: West Group, 2002.

JONES, J. M. In U.S., positive attitudes toward foreign trade stay high. Gallup, 1 Mar. 2018.

LERNER, S. Before pushing tariffs, Wilbur Ross had a messy history with the U.S. steel industry. The Intercept, 5 Mar. 2018. Disponível em: <https://bit.ly/2Fx0Gde>. LEVINSON-KING, R.; PALUMBO, D. Donald Trump v the world: US tariffs in four charts. BBC, 3 Dec. 2018. Disponível em: <https://bbc.in/2rUtrbc>.

MENDONÇA, F. Entre a teoria e a história: a política comercial dos Estados Unidos na década de 1980. São Paulo: Editora Unesp, 2011. 
MENDONÇA, F.; LIMA, T. A política comercial dos Estados Unidos no governo Obama: heranças, estratégias e desafios. In: MORAES, R. C. C. de; MENEZES, H. Z. (Org.). A economia política do governo Obama. João Pessoa: Editora UFPB, 2017. p. 121-164.

MENDONÇA, F.; LIMA, T.; VIGEVANI, T. Instituições e política comercial nos Estados Unidos: política internacional, demandas domésticas e design institucional. Economia e Sociedade, v. 26, n. 1 (59), p. 45-77, abr. 2017.

. Poder e comércio: a política comercial dos Estados Unidos. São Paulo: Editora Unesp, 2018.

MURPHY, C. N. Organizaçáo internacional e mudança industrial: governança global desde 1850. São Paulo: Editora Unesp, 2014.

NAVARRO, P.; AUTRY, G. Death by China: confronting the dragon - A global call to action. New York: Pearson Prentice Hall, 2011.

NAVARRO, P.; ROSS, W. Scoring the Trump economic plan: trade, regulatory, and energy policy impacts. Peterson Institute for International Economics (PIIE), Washington, D.C., 29 Sept. 2016. Disponível em: <https://bit.ly/2daD 7H3>.

PARILLA, J.; MURO, M. Where global trade has the biggest impact on workers. Brookings, 14 Dec. 2016.

RODRIK, D. Populism and the economics of globalization. Journal of International Business Policy, 2018. Disponível em: <https://bit.ly/2suIFDf $>$. Acesso em: 2 dez. 2018.

ROSECRANCE, R. N. The rise of the trading state: commerce and conquest in the modern world. New York: Basic Books, 1986.

SANCHEZ, L. Fox News host calls out Wilbur Ross over conflicts of interest on investments. The Hill, 11 June 2018a. Disponível em: <https://bit.ly/2YvcPVf>.

Schumer praises Trump for China tariffs. The Hill, 17 June 2018b. Disponível em: <https://bit.ly/2YvFiug>.

SCHWAB, S. C. After Doha: why the negotiations are doomed and what we should do about it. Foreign Affairs, May/June 2011.

SEBENIUS, A.; MAYEDA, A. Trump, Xi hail progress in trade talks as tariff deadline nears. Bloomberg, 15 Feb. 2019. Disponível em: <https://bloom. bg/2SRjtGx>.

SIRIPURAPU, A. China weighs additional tariffs on $\$ 60$ billion worth of U.S. goods. World Trade Online, 3 Aug. 2018. Disponível em: <https://bit.ly/333fIQI>. 
SOLOMON, D. B. Who is Peter Navarro? He said there's a "special place in hell" for Trudeau. The New York Times, 11 June 2018. Disponível em: <http://bit. do/faM9N>.

SWAN, J. Trump vents in Oval Office, "I want tariffs. Bring me some tariffs!". Axios, 27 Aug. 2017. Disponível em: <https://bit.ly/334RQvS>.

UNITED STATES OF AMERICA. Office of the Press Secretary. Press briefing by secretary of commerce Wilbur Ross on an executive order on trade agreement violations and abuses. The White House, 28 Apr. 2017. Disponível em: <https://bit.ly/2OwuCM1>.

. Department of Agriculture. USDA assists farmers impacted by unjustified retaliation. USDA, Washington D.C., 24 July 2018a. Disponível em: $<$ https://bit.ly/2OfOZZF>.

. Executive Office of the President. USTR finalizes second tranche of tariffs on Chinese products in response to China's unfair trade practices. Office of the United States Trade Representative, Washington D.C., 8 June 2018b. Disponível em: <https://bit.ly/2M0CQup>. Acesso em: 9 mar. 2019.

. Executive Office of the President. USTR finalizes tariffs on $\$ 200$ billion of Chinese imports in response to China's unfair trade practices. Office of the United States Trade Representative, Washington D.C., 18 Sept. 2018c. Disponível em: <https://bit.ly/2xuKv9U>.

. Executive Office of the President. USTR issues tariffs on Chinese products in response to unfair trade practices. Office of the United States Trade Representative, Washington D.C., 15 June 2018d. Disponível em: <https://bit.ly/2MtOfQ2>.

. Department of Commerce. Global steel trade monitor. International Trade Administration, Sept. 2018e. Disponível em: <https://bit.ly/2CTjdLh>.

. Executive Office of the President. Trump administration charts trade policy course more favorable to American workers. Office of the United States Trade Representative, Washington D.C., Mar. 2019. Disponível em: <https:// bit.ly/2SZS3vH>.

VILLARREAL, M. A.; FERGUSSON, I. F. The North American Free Trade Agreement (NAFTA). Congressional Research Service, Washington D.C., p. 43, 2017.

YORK, E. President Trump announces two steep tariffs on steel and aluminum. Tax Foundation, 2 Mar. 2018. Disponível em: <https://bit.ly/2OsPTX1>.

YU, C. Trade war not driven by ideology, says director at Tsinghua University. China Daily, 13 July 2018. Disponível em: <http://bit.do/fbjCT>. 


\section{BIBLIOGRAFIA COMPLEMENTAR}

COLLINS, M. U.S.-Mexico are close to reaching a deal in NAFTA talks, but Canada is still a wild card. USA Today, 14 Aug. 2018. Disponível em: $<$ https://bit.ly/2ZoV8b8>.

GRAHAM, D. How Trump split Mexico and Canada in NAFTA talks. Reuters, 25 Sept. 2018. Disponível em: <https://reut.rs/2zsFbXb>.

LAM, P. Peter Navarro. Investopedia, 25 Jun. 2019. Disponível em: <https:// bit.ly/2Kjhwwg>.

LAWDER, D. U.S. trade rep says in NAFTA talks he keeps Trump's views in mind. Reuters, 5 Sept. 2017. Disponível em: <https://reut.rs/32ZITEe>.

RAPPEPORT, A.; PORTER, C.; MALKIN, E. Trudeau sought support from Mexico's president on NAFTA. The New York Times, 28 Sept. 2018. Disponível em: <https://nyti.ms/2ZosM0L >.

TAYLOR, A. A timeline of Trump's complicated relationship with the TPP. The Washington Post, 13 Apr. 2018. Disponível em: <https://wapo.st/2YAhrcT>.

TUNNEY, C. No NAFTA without cultural exemption and a dispute settlement clause, Trudeau vows. CBC, 5 Sept. 2018. Disponível em: <https://bit.ly/2LYavjs>. UNITED STATES OF AMERICA. United States Trade Representative. The Trans-Pacific Partnership. 2015. Disponível em: <https://bit.ly/2cRettI >.

VILLARREAL, M. A.; FERGUSSON, I. F. The North American Free Trade Agreement (NAFTA). Congressional Research Service, Washington D.C., p. 43, 2017.

WILBUR Ross fast facts. CNN, 9 Aug. 2019. Disponível em: <https://cnn. it $/ 2 Y \times 1 \mathrm{rMS}>$. 


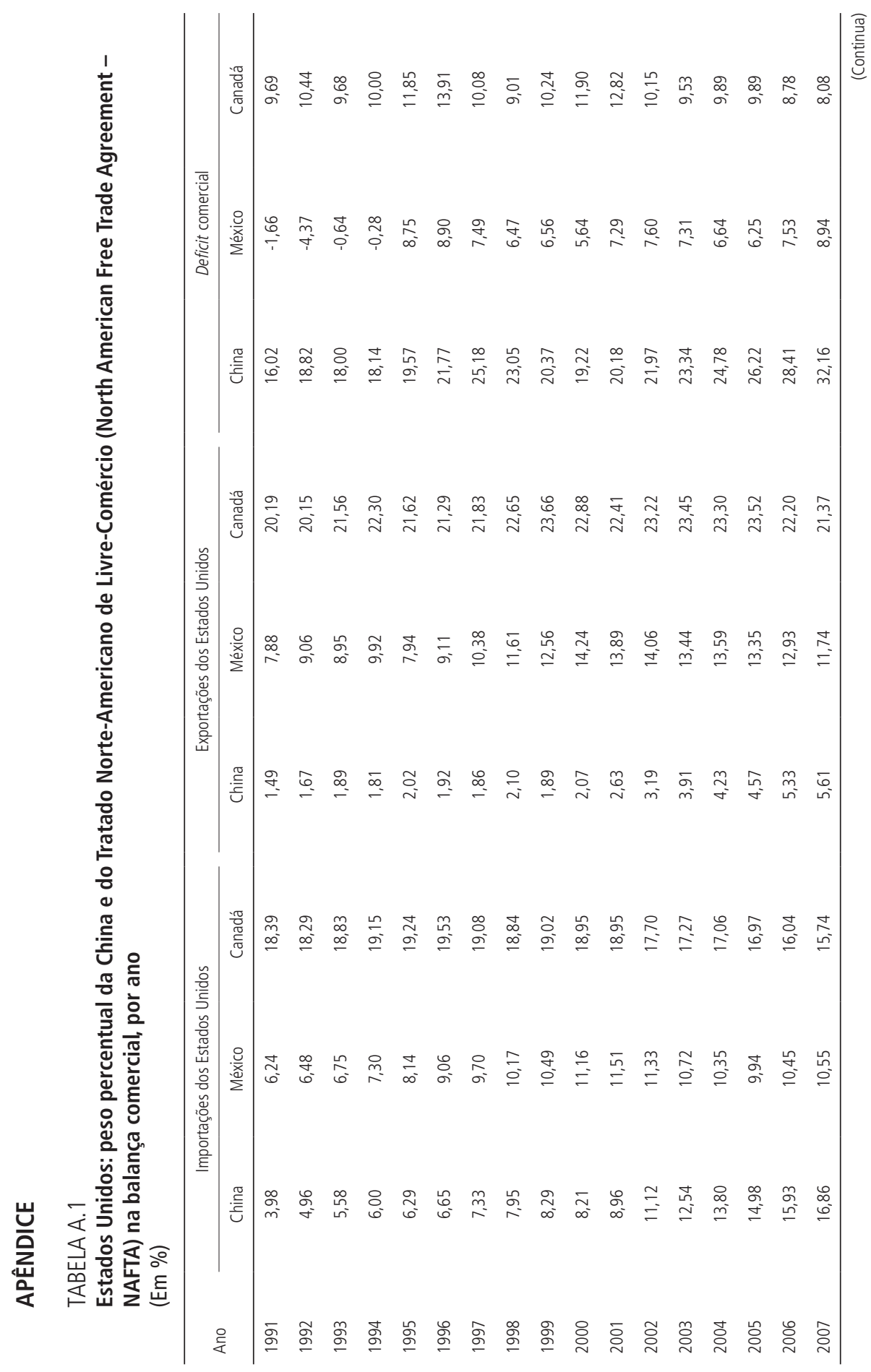




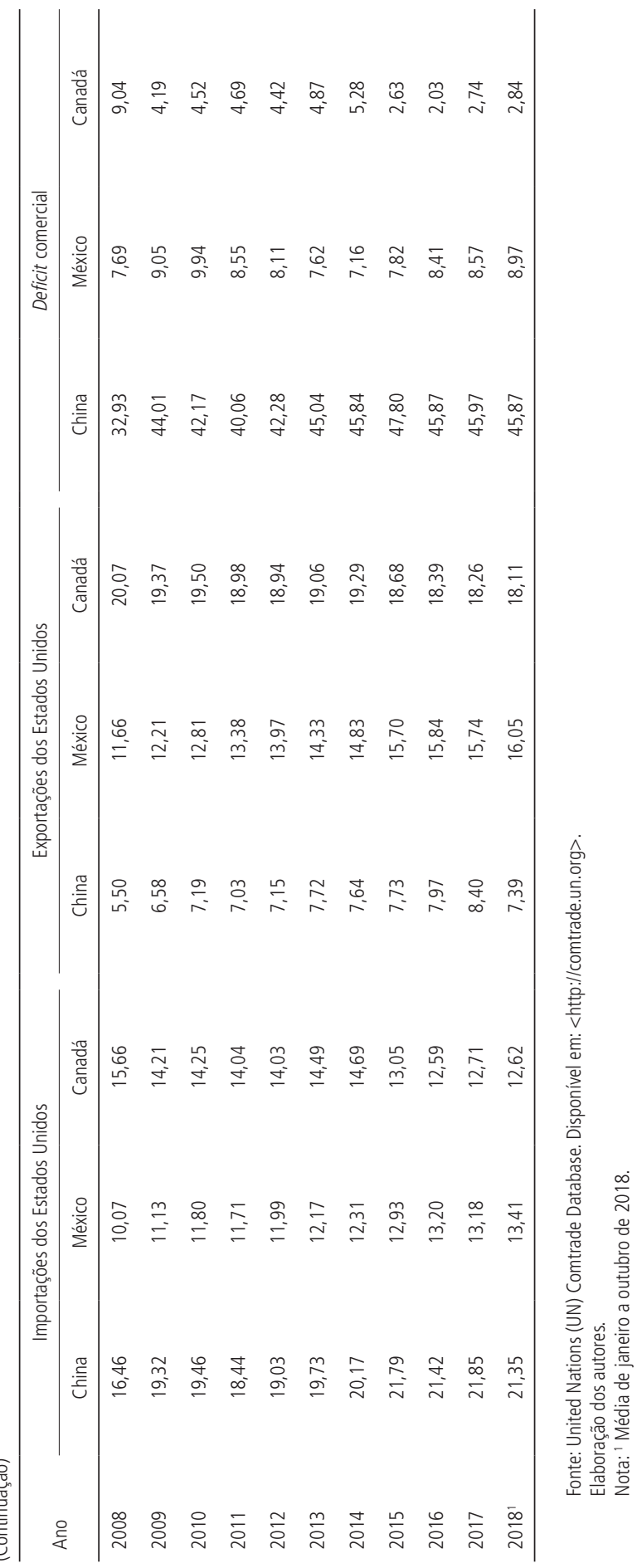


"America First But Not Alone": uma (nem tão) nova política comercial dos Estados Unidos com Donald Trump

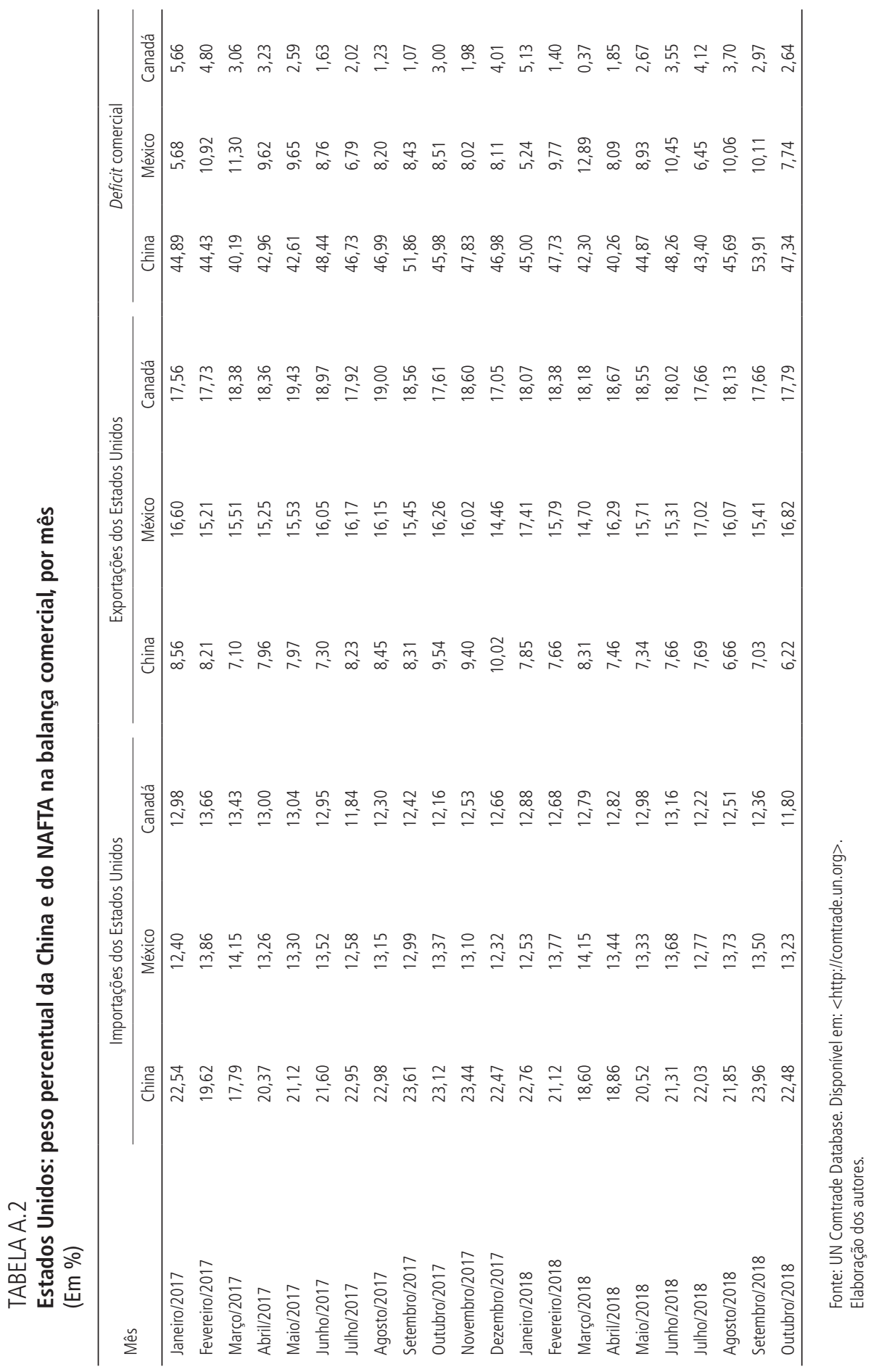




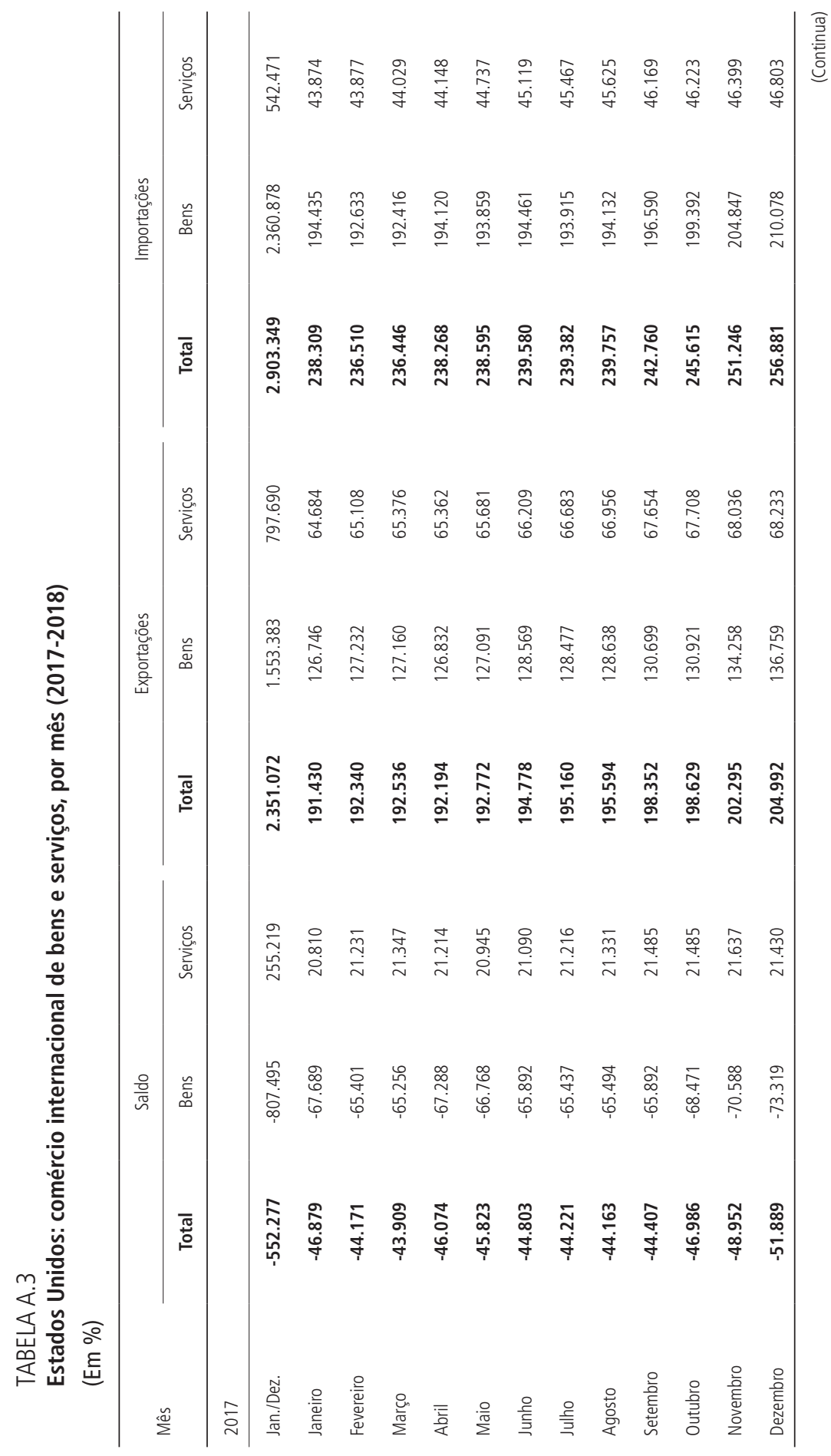


"America First But Not Alone": uma (nem tão) nova política comercial dos Estados Unidos com Donald Trump

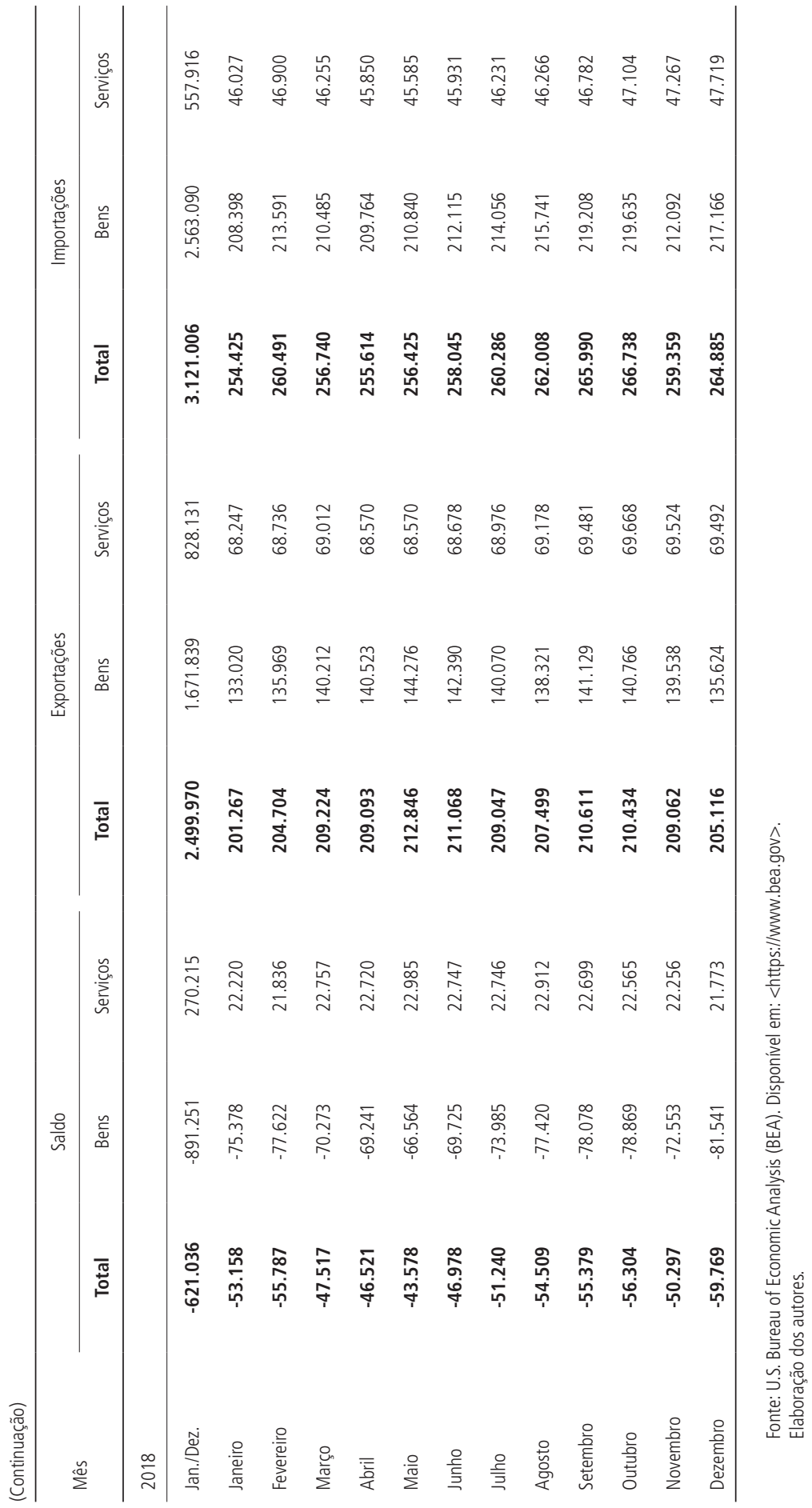


